Article

\title{
Understanding Household Waste Separation Behaviour: Testing the Roles of Moral, Past Experience, and Perceived Policy Effectiveness within the Theory of Planned Behaviour
}

\author{
Lin $\mathrm{Xu}{ }^{1}$, Maoliang Ling ${ }^{1}$, Yujie Lu ${ }^{2, *}$ and Meng Shen ${ }^{2}$ \\ 1 School of Public Affairs, Zhejiang University, Hangzhou 310058, China; xulin0707@zju.edu.cn (L.X.); \\ lingmaoliang@zju.edu.cn (M.L.) \\ 2 Department of Building, School of Design and Environment, National University of Singapore, \\ Singapore 117566, Singapore; mengshen@nus.edu.sg \\ * Correspondence: luy@nus.edu.sg; Tel.: +65-651-658-94
}

Academic Editor: Vincenzo Torreta

Received: 12 March 2017; Accepted: 12 April 2017; Published: 17 April 2017

\begin{abstract}
Due to the increasing waste generation over the years in China, there is an urgent need to addressing this major problem by implementing effective household waste separation programs. Although past studies have tried to explain the waste behaviour from social and psychological motivations, there is little understanding as to the impact of individual moral obligation and past experience on forming waste separating intention. The aim of this study is to investigate key determinants influencing household waste separation intention and behaviour. Based on the theory of planned behaviour (TPB) model, we designed a survey questionnaire by taking account of determinants including residents' attitude, subjective norm, perceived behavioural control, moral obligation, past behaviour, and demographic factors, with the prediction of household waste separation behaviour in mind. After obtaining 628 valid questionnaires from households in the city of Hangzhou, the partial least squares structural equation modelling (PLS-SEM) was conducted to evaluate the effectiveness of each construct. The results indicate that subjective norms, perceived behavioural control, past behaviour and intention significantly predict household waste separation behaviour, with past behaviour being the most significant construct to predict individuals' intention and behaviour. Additional analysis on the moderating effect of different kinds of people in terms of their genders, ages, income levels and perceived policy effectiveness, to further evoke household waste separation behaviours is also discussed. The findings suggest insightful future policies that can focus on residents' habit formation by providing the convenient location of waste separation and collection facilities, encouraging market-driven recycling programs and traders, promoting community campaigns and education which help residents to form favourable habits for protecting the environment.
\end{abstract}

Keywords: household waste separation; waste classification; theory of planned behaviour; recycling behaviour; perceived policy effectiveness; PLS-SEM

\section{Introduction}

Considering the rapid increase in population and development along with the intense increase in household solid waste generation that causes a significant impact on the environment degradation and human health in China, various waste sorting initiatives have been gathering momentums across this country since 2000. Household waste commonly consists of garbage such as paper, electronic equipment, leftover food, plastic and glass bottles, metal cans and clothing discarded form homes. 
Waste separation, also known as waste classification or waste segregation, is the process by which waste is separated into different elements operated manually at the household or through curbside collection schemes. With "garbage sieges" becoming increasingly serious In China, the policy of separating household waste for disposal has been raised to an unprecedented level: Beijing, Shanghai, Nanjing, Hangzhou, Guilin, Guangzhou, Shenzhen and Xiamen are the first batch of cities to pilot waste separation schemes. Furthermore, the National Development and Reform Commission (NDRC) and Ministry of Housing and Urban-Rural Development (MoHURD) jointly issued their "Mandatory Waste Separation System Program (Draft)" in June 2016, highlighting the urgency and importance of this work. In essence, the residents' active involvement in carrying out pro-environmental behaviour plays a key role in implementing successful household waste management programs [1]. However, results have shown that household waste source separation in these cities was not successful enough due to the lack of participation from the residents. To bridge this gap, it is critical to explore and understand the drivers and barriers behind resident's waste separation behaviour, in order to facilitate the public participation in the waste separation programs and reconcile the irrationality of collective action in China.

Prior studies on household waste separating have focused mainly on four aspects, namely: techniques of waste separation, effectiveness of waste recycling policies or programs, the partnerships between various sectors in waste management and key determinants of individual separating behaviour. The main aim of technological-oriented researches is to develop clean, convenient and economical methods to sort the household waste [2,3]. Meanwhile, a few researchers have discussed the effectiveness of waste policies or programs such as curbside recycling and education carefully [4-6]. Also, Dinan demonstrated the advantage of refundable deposit policy in the case of illegal dumping [7]. Scholars also appeal to the cooperation and partnerships between public authorities, private companies and social organisations in the process of waste separation and disposal to promote the waste reuse and reduction, which can improve urban healthcare and employment as well [8-10].

It is acknowledged that the participation of residents in waste separation is of critical importance for waste management, and there are increasing literatures investigating the key influencing factors of separating behaviour of residents [11-16]. As people's behaviours are mainly affected and dominated by psychological factors, it is necessary to identify the internal and external factors accountable for waste separation behaviour. Schwartz's Norm Activation model [17], Theory of Reasoned Action (TRA), and Theory of Planned Behaviour (TPB) [18] are some of the behavioural theories that have been applied in previous studies to investigate the factors of separating behaviour. Schwartz's Norm Activation model mainly focuses on the awareness, responsibility and personal norm while TRA more focuses on the attitude and social norms of individuals. As an improvement of TRA, the TPB model also incorporates the perceived behaviour control and has been widely used in studies on waste separating behaviours and other various research areas to evaluate and predict user's behaviours, such as the analysis of health behaviours [15]. As TPB has been the most supportive psychological model for assessing the factors of behaviour, it is then selected as the basis of this research.

\subsection{Theory of Planned Behaviour (TPB)}

The TPB provides a theoretical conceptual model to methodically investigate the influence of constructs towards behaviour. The theory expresses that attitude, subjective norm, and perceived behavioural control, together shape an individual's intention and behaviour (see Figure 1) [18]. To be more specific, behavioural intention reflects one's determination of subjective probability and the willingness to adopt a particular action. Separating attitude has been considered as a responsibility and subjective evaluation of an individual's opinion towards an object [19], and it is consistently shown related to separating behavioural intention. Particularly, attitude is an important variable for understanding one's separating actions, as well as a strong estimate on whether an individual is willing to recycle the refuse [20]. Subjective norm is known as the social pressure stemming from the salient social referents such as family, friends, neighbours, colleagues and even government and mass 
media and perceived by a person [21], which can affect an individual's behavioural intention [22]. When people are unsure of the right thing to do, they would tend to draw their inference by observing others' behaviour, therefore their behaviours are influenced by social pressure. For example, if an actor encounters a contradictory in behavioural attitude compared with someone important, he or she maybe change the initial idea [23], which supports that subjective norm could be indirectly related to one's behaviour.

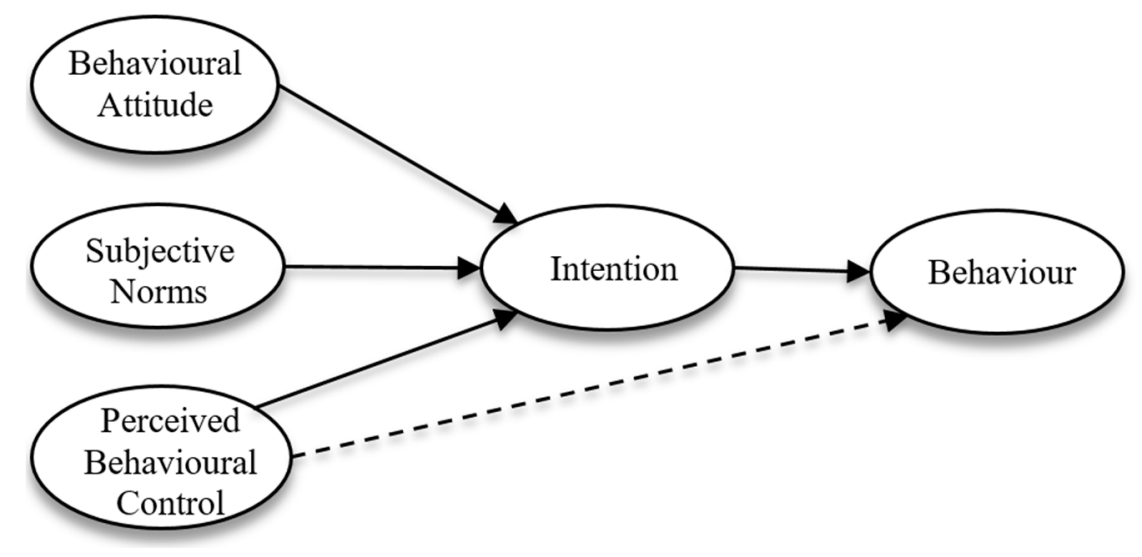

Figure 1. Conceptual model of theory of planned behaviour (TPB), adapted from Ajzen [18].

Furthermore, according to TPB, perceived behavioural control is one of the direct constructs in predicting intention and behaviour. Perceived behavioural control describes one's opinion on the possession of behavioural resource [24] and reflects performer's perceived difficulty or ease in performing a particular task [12]. It reviews an individual's perceived control over factors, such as development of information and skills, will power, time and convenience. In addition, the intention is a self-regulation approach that transforms righteous attitude or believes into action, which can be regarded as a post-intentional procedure that influences a deliberate action [1]. Besides, studies also show that an individual's intention can effectively influence the performance of behaviour [15]. It has previously always been introduced to bridge the attitude-behaviour gap [25]. Up to now, the model of TPB has been applied to explore individual and/or household behaviours, such as food waste reduction [26-28] and waste recycling [1,12,29], which manifests its effectiveness in analysing and predicting the household waste separation behaviours.

\subsection{Other Possible Influential Factors on Pro-Environmental Intention and Behaviour}

Although TPB provides a rational guide for assessing how the psychological factors influence the pro-environmental behaviour, scholars have considered other factors such as perceived moral obligation, past behaviour, demographic characteristics and perceived policy effectiveness may also influence behaviour in TPB model for a more accurate prediction $[1,18,30,31]$.

The perceived moral obligation has been defined as an individual's judgement of moral rightness to carry out one certain behaviour. Ajzen suggested that perceived moral obligations should be included to enhance better predictive validity [18,32]. More precisely, perceived moral obligations indicate that the self-expectation and responsibility motivates people to be environmentally-friendly. A study in Vietnam showed that moral obligations had a significant positive effect on conservation behaviour [33]. Similar findings have also been validated in a few research papers analysing the recycling behaviour of Chinese residents [29,34].

Moreover, past behaviour may also be a key factor in predicting household waste intention and behaviour. Barr and Gilg discussed that past behaviour is a self-reinforcing process which provides an important reference for subsequent behaviour [35], hence an individual who conforms to a particular behaviour will be more inclined to perform it again. 
With respect to the effects of demographics characteristics, various studies have been conducted to justify the relationship between demographic variables and pro-environmental behaviour [1]. For instance, a study selected 2400 householders from Iran to evaluate the correlation between demographic, attitude, knowledge and other factors relevant to waste disposal. The results showed that their knowledge, attitudes, and practices towards solid waste recycling were influenced by demographic factors of age, education level, gender and occupation [11]. Another example is that individuals' education level can help to predict pro-environmental behaviours [36]. However, Botetzagias added education, gender, income and age as independent variables into the TPB model and found no significant correlation between pro-environmental behaviour and demographic factors [37]. Therefore, in order to explain the contradiction of previous studies, this paper focuses on the moderating effects of demographic factors rather than direct effects on endogenous variables to understand the applicability and diversity of the extended TPB model in different populations.

In addition, the effective campaign and education of waste separation policies can promote residents' participation in waste separation programs [38], and Wan et al. further revealed that the perception of whether the separation policy can successfully achieve the goals of reclamation and reduction is also an important motivation to perform such behaviour [39], which has been ignored by most researchers. Moreover, they discussed and demonstrated the moderating effect of perceived policy effectiveness on recycling intention based on a survey in Hong Kong [40]. Thus, the residents' perceived policy effectiveness functioned as a perception of external or situational factor and this is assumed to generate a profound impact on the relationships between psychological determinants, intention and separating behaviour.

Although the discussed factors including perceived moral obligation, past behaviour, demographic factors and perceived policy effectiveness may also influence pro-environmental intention and behaviour. However, they have not been completely tested yet in the context of household waste separation behaviour. Especially in China, the Confucian-oriented moral values featuring altruism and austerity may facilitate pro-environment behaviour. Moreover, the resource conversation awareness influenced by the traditional culture and custom also helps public form the habits of recycling and reuse. These past behaviours or habits would function as a reminder for residents to discipline themselves and a guideline to determine action (or inaction) according to the self-cognitive theory [31]. Additionally, the omnipotent government in authoritarian system usually has a strong ability to intervene private-sphere actions of residents, whose perception of effective separation policy may also promote their performance. Meanwhile, the uneven national environmental awareness induces a big heterogeneity in pro-environmental willingness and actions among populations with different age, gender, income or education. Therefore, these variables should be included in this study focusing on the separating behaviour of Chinese residents to a greater extent.

Specifically, this paper aims to discuss and examine the key psychological and demographic determinants influencing household waste separation behaviour of residents in Hangzhou by using the extended TPB model from social psychology. To this end, the well-prepared questionnaires on current waste separation participation initiatives were distributed to local household residents randomly. The questions are designed in accordance with the possible psychological and demographic factors which can further help to understand the deeper causes of residents' actions. Subsequently, a partial least squares structural equation modelling (PLS-SEM) is applied to examine the effects of each factor. Finally, the roles of demographic characteristics and perceived policy effectiveness for predicting residents' behaviour are discussed.

The remaining parts of the study are structured as follows. Section 2 constructs the extended TPB model and identifies the main hypotheses. Section 3 provides the empirical results of our survey conducted in Hangzhou, China. Section 4 presents the discussion, and further explores and assesses the moderating effects of demographic factors and perceived policy effectiveness on endogenous variables in our extended TPB model, followed by the conclusion presented in Section 5. 


\section{Methods}

\subsection{Conceptual Framework and Research Hypothesis}

Targeting waste separation behaviour, a conceptual framework target showing the extended TPB model that adopted in this study with its indicated hypotheses is presented in Figure 2.

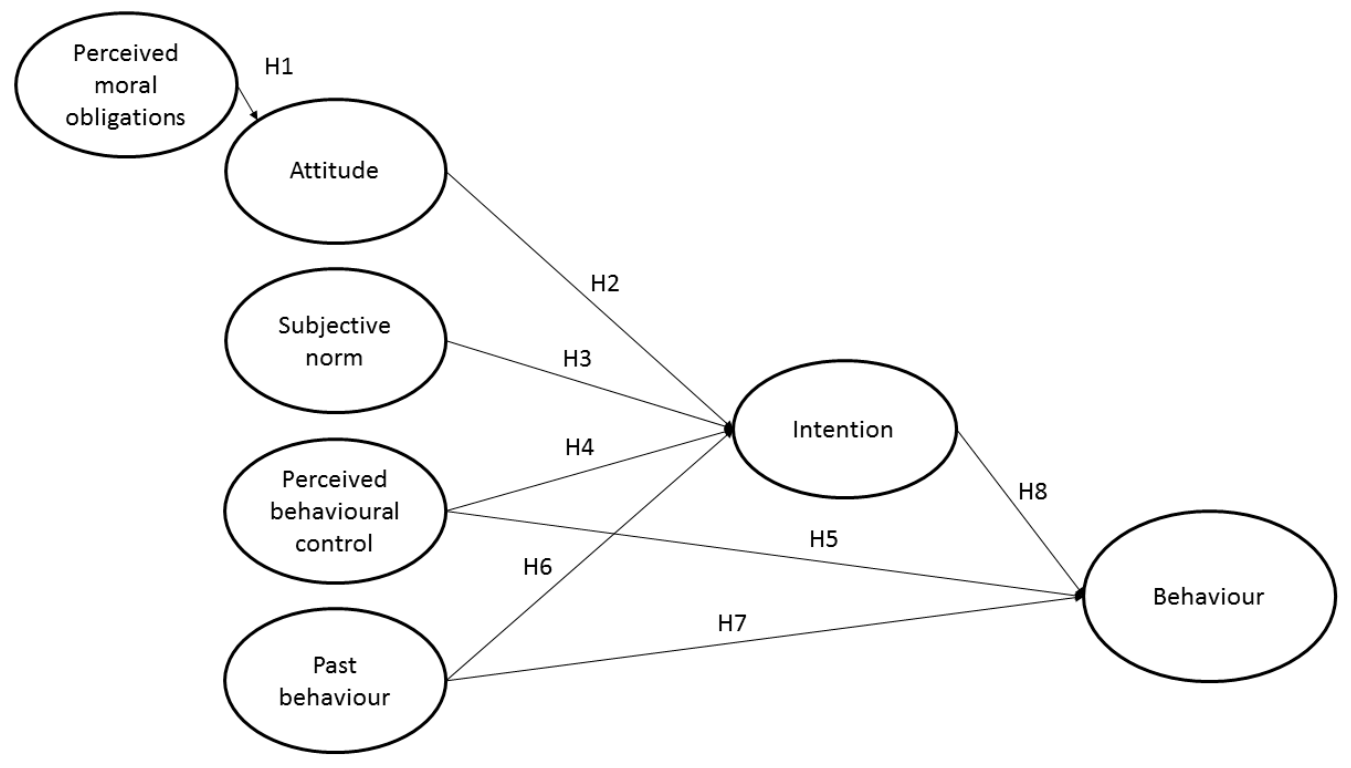

Figure 2. Proposed conceptual model.

Attitude that stresses moral obligation towards the environment draws attention to personal beliefs on rights and responsibilities [35]. Hence, an individual who has a high perception of moral obligations often manages their thoughts and follow the discipline, which may enhance a stronger attitude towards being environmental-friendly. In addition, researches find that individual's attitude is strongly correlated with intention on waste separation [41]. Hence, a man with positive attitude would be more willing to reduce pollution and conserve resources [42]. Accordingly, the following hypotheses can be concluded:

Hypothesis 1 (H1). Perceived moral obligations have a positive influence on attitude.

Hypothesis $2(\mathrm{H} 2)$. Attitude towards waste separation has a positive effect on waste separation intention.

There are studies which found that an individual's intention on recycling behaviour is adequately influenced by the expectation of salient referent groups $[43,44]$. Therefore, subjective norm is positively related to an individual's waste separation intention. This understanding leads to the following hypothesis:

Hypothesis 3 (H3). Subjective norm has positive influence on waste separation intention.

According to Telesiene and Gross, there is a strong direct effect of perceived behavioural control on intention and pro-environmental behaviour [42]. More opportunities and resources with less expected obstacles a person perceives would increase the willingness and chance to perform a particular behaviour. Ajzen proposed that perceived behavioural control assists as a substitute for actual behavioural control which can be utilised directly to predict intention and behaviour to overcome barriers when perceived and actual behaviour control coincide [18]. The direct path from perceived behavioural control to intention/behaviour is assumed to display the influence between actual ease 
and difficulty with intention/behaviour. In this study, a significant path from perceived behavioural control to intention or behaviour would suggest that people will be more likely to perform waste separation behaviour when they have a higher perceived behavioural control.

Therefore, the following hypotheses can be concluded:

Hypothesis 4 (H4). Perceived behavioural control has a positive influence on waste separation intention.

Hypothesis 5 (H5). Perceived behavioural control has a positive effect on waste separation behaviour.

Past behaviour is an action done previously or a habit, which stimulates an individual to have the intention to perform the same action again in the future. Early studies have concluded that past behaviour has an influence on intention and behaviour without any interference [45,46]. According to self-cognitive theory, an individual could realise the pursuit of self-knowledge and make the subsequent choice by means of observing his or her initial performance. Hence, when a person has past experience in carrying out waste separation, he or she may have a greater intention to perform it repeatedly. Besides, past behaviour indicates that an individual's habit could also directly establish future behaviour [47]. Therefore, when a person has past behaviour in carrying out waste separation, there is a high possibility that past behaviour transforms into intention and actual behaviour. Accordingly, the following hypotheses can be proposed:

Hypothesis 6 (H6). An individual's past behaviour has a positive effect on waste separation intention.

Hypothesis 7 (H7). An individual's past behaviour has a positive effect on waste separation behaviour.

As the original TPB model shows, the intention is associated with attitude, subjective norms, and perceived behavioural control, which also has a strong effect on actual behaviour. This insight leads to the following hypothesis:

Hypothesis 8 (H8). Separating intention has a positive influence on waste separation behaviour.

\subsection{Survey Area}

Hangzhou is one of the first pilot cities in China that implement management of source separation of waste. However, there has still been a rapid growth in the household waste generation over the last ten years. To cope with this crisis, the municipal government issued a "Hangzhou Municipal Waste Management Regulations" in 2015 to encourage public participation in waste separation. The JB Street located at the east of Hangzhou has already began implementing innovative approaches towards waste separation since 2011 and has had a great effect, which has also received the attention of central government and been popularised in the whole country. As a demonstration zone of Hangzhou, the JB Street is selected as the survey area of this study.

\subsection{Questionnaire Design}

A waste separation behaviour questionnaire is designed based on the previous literatures. At the first stage, a preliminary questionnaire was sent out to 220 participants including residents, experts of solid waste management sector, government staffs and social workers of JB Street. Through 87 feedbacks obtained from 220 participants, the related items and structure of questionnaire were modified accordingly. At the second stage, the modified questionnaires were distributed to 24 residents of JB Street to conduct a small-scale preliminary research, after which, further modifications of the questionnaire for this study were done based on the feedbacks received from residents. The complete questionnaire is shown in Appendix A. 


\subsubsection{Independent Variables}

Attitude towards waste separation was measured by 6items to indicate value judgement on waste separation, perceived social benefits and self-interest. For example, "waste separation helps to protect the environment and conserve resources, we should do it". The adjective 5-point Likert-scale ranging from 1 to 5, representing "strongly disagree", "disagree", "not necessarily", "agree" and "strongly agree", was used for respondents to rate each item. Higher scores reflect a more positive attitude towards waste.

Subjective norm was assessed by 11 items reflecting the expectations or supports from social salient references such as family members, neighbours, friends, colleagues, government, organizations and mass media, and the willingness of respondents to comply with them. For instance, "do your family support you in performing waste separation?", "if your family encourage you in implementing waste separation, are you willing to listen to their advice?" Each question was rated on the same 5-point Likert-scale, ranging from "strongly disagree" to "strongly agree".

Twelve items used to assess perceived behavioural control focused on the possession and importance of various behavioural resources. For example, "do you have enough time to carry out waste separation?" and "If you do not have enough time, will you still carry out waste separation?" Each item was measured on a 5-point scale, namely "totally no time", "do not really have time", "depends on situation", "often have time" and "always have time".

Perceived moral obligation was measured by three items to reflect moral judgement for waste separation. For instance, "waste separation is a thrifty ethical behaviour, everyone has a duty to do so." Each item was answered by a 5-pointed method, namely "strongly disagree", "disagree", "not necessarily", "agree" and "strongly agree".

Past recycling behaviour was measured by two items like "over the past one month, do you practice waste separation regularly?" This item was scored on a 5-point Likert-scale, namely "not at all", "seldom", "average", "often" and "all the time".

\subsubsection{Dependent Variables}

Waste separation intention was measured by two items, "starting from next week, will you prepare to carry out waste separation?" and "how many days are you willing to carry out waste separation?" Each item was scored on a 5-point Likert-scale, namely "totally impossible", "almost impossible", "depends on situation", "very likely" and "definitely will" as well as "0 day", "1-2 days", "3-4 days", "5-6 days" and "everyday".

Waste separation behaviour was measured by separating frequency of nine different types of waste such as waste paper, discarded batteries, electronic equipment, kitchen waste, discarded plastic bottles, cans, metal, renewable plastics, glass bottles and fabrics over the past year. Each item was scored on a 5-point Likert-scale namely "never collect at all", "seldom collect", "collect occasionally", "collect regularly" and "always collect".

\subsubsection{Moderating Variables}

Both residents' demographic characteristics and individual perceived policy effectiveness are set for the moderating variables. Demographics include residents' gender, age, income, education and occupation. Perceived policy effectiveness was measured by five items that represent different perceptions of effectiveness of governmental policies on waste separation, including informational campaign and provision of convenient separation facilities. Each of items was answered by 5-point Likert-scale and shown in Appendix A.

\subsection{Data Analysis Method}

To test the proposed conceptual model, the partial least squares structural equation modelling (PLS-SEM) using SmartPLS software was adopted in this study. Compared with the covariance-based 
structural equation modelling (CB-SEM) that is commonly adopted in previous works related to TBP model $[12,48,49]$, PLS-SEM has its merits for this research due to its extensive applicability for different types of data and its ability to examine the preliminary and exploratory theories. To be specific, (1) it can be used to determine the factor that have the most effect on the dependent variable, (2) it is a more suitable data analysis method when the normality test is not available, (3) construct with less than three questions are also suitable for PLS-SEM, (4) it can avoid the difficulties with estimating stable factor scores, and can produce more defined estimation of factor scores as the algorithm calculates latent variable scores as exact linear combinations of the observed indicator variables.

\section{Sampling and Data Analysis}

The survey was conducted in March and April of 2016 within seven communities in JB Street, in which there are approximately 27,000 residents and 16,000 households. The street surveys were disseminated to the households through systematic sampling. The questionnaire exclusively for adults (residents with 18 years or older) was either posted to individual household with return postal stamps or through face-to-face interviews in resident's homes. Among the population of JB Street, a total of 1575 questionnaires were sent out and 1234 questionnaires completed were obtained, and the response rate was $78.3 \%$. To ensure the quality of questionnaires, representatives from the research group were present at the study site to answer queries from residents and collect the completed questionnaires. Invalid questionnaires with the presence of a large number of unfilled answers, insufficient information of demographic characteristics, and selection of same option throughout the questionnaire were excluded in this study and ultimately, 628 valid questionnaires were obtained. Babbie and Kidder et al. regarded that $50 \%$ is an acceptable response rate in social research surveys [50,51], hence, a $50.9 \%$ of valid questionnaires is eligible for this research.

A series of data analysis processes have been conducted in this section. In the following subsections, a descriptive analysis is presented to understand the characteristics of demographic factors and target variables. Subsequently, the scientific relevance and effectiveness of the structure model through Cronbach's alpha and Fornell's measure of composite reliability is validated. Finally, the structure model has been evaluated to test the main hypotheses. The PLS-SEM is performed using SmartPLS 3.0 to analyse the measurement model and the association between the constructs for the prediction of household waste separation behaviour.

\subsection{Descriptive Statistic}

The basic demographic profile of the study sample is shown in Table 1. Females and 31-40 years old represent $52.7 \%$ and $38.8 \%$ of the sample size respectively. The age of respondents ranges from 19 to 89 years old, with the middle group of $31-50$ years old accounting for $54.6 \%$. Moreover, $57.6 \%$ of the respondents are at the high education level (college) and $54.6 \%$ of respondents' families earns more than the average salary of CNY 10,000 in Hangzhou [52], and nearly half of respondents worked in companies. The sample characteristics are similar to the latest census available in Hangzhou (Census data can be retrieved in the 2016 statistics yearbook of Hangzhou, available online: http: //www.hzstats.gov.cn/web/tjnj/nj2016/02nj_.html, (accessed on 6 April 2017). However, the ratio of education level, which cannot be found in any published data, came from a randomly sampling survey conducted in Hangzhou by Municipal Bureau of Statistics in 2016.), with slightly higher percentages in female (52.7\% rather than 50.2\%) and in well-educated (57.6\% than $43.6 \%)$. It is worth noting that there are $15.5 \%$ of the population are youngsters ( $<18$ years) but they are not included in this study as the scope of survey is limited to adults.

The descriptive statistical analyses for each of the independent variables are shown in Table 2. The mean of all the independent variables are relatively high, indicating that the majority of the residents provide positive responses on waste separation. Besides, the standard errors of all variables are relatively small, indicating that the mean is reasonably close to the true mean of overall sample. All variables are relatively concentrated around the means because their standard deviation values are 
less than 1 . The negative skewness of all variables explains an asymmetrical distribution that the data set falls towards the higher side of the scale and there are very few lower values.

Table 1. Demographic profile of respondents.

\begin{tabular}{|c|c|c|}
\hline Demographics & Number of People & $\%$ of The Total Samples \\
\hline \multicolumn{3}{|l|}{ Gender } \\
\hline Male & 297 & 47.3 \\
\hline Female & 331 & 52.7 \\
\hline \multicolumn{3}{|l|}{ Age } \\
\hline$<20$ & 2 & 0.3 \\
\hline $20-30$ & 165 & 26.3 \\
\hline $31-40$ & 244 & 38.9 \\
\hline $41-50$ & 99 & 15.8 \\
\hline $51-60$ & 62 & 9.9 \\
\hline$>60$ & 56 & 8.9 \\
\hline \multicolumn{3}{|l|}{ Education level } \\
\hline No education & 4 & 0.6 \\
\hline Primary school & 26 & 4.1 \\
\hline Junior high school & 93 & 14.8 \\
\hline High school & 143 & 22.8 \\
\hline Junior college & 144 & 22.9 \\
\hline Undergraduate & 201 & 32.0 \\
\hline Graduate and above & 17 & 2.7 \\
\hline \multicolumn{3}{|l|}{ Occupation } \\
\hline $\begin{array}{l}\text { Government organizations, } \\
\text { undertaking employment, army }\end{array}$ & 104 & 16.6 \\
\hline Company business & 287 & 45.7 \\
\hline Social group & 26 & 4.1 \\
\hline Self-employed & 73 & 11.6 \\
\hline Retirement & 72 & 11.5 \\
\hline Others & 66 & 10.5 \\
\hline \multicolumn{3}{|c|}{ Monthly household income after tax $\left(\mathrm{CNY}^{\mathrm{a}}\right)$} \\
\hline$<5000$ & 77 & 12.3 \\
\hline $5000-10,000$ & 208 & 33.1 \\
\hline $10,001-15,000$ & 167 & 26.6 \\
\hline $15,001-20,000$ & 94 & 15.0 \\
\hline $20,001-25,000$ & 43 & 6.8 \\
\hline$>25,000$ & 39 & 6.2 \\
\hline
\end{tabular}

${ }^{\text {a }}$ Currency code of Chinese Yuan.

Table 2. Descriptive statistics.

\begin{tabular}{cccccc}
\hline Attitude & $\begin{array}{c}\text { Subjective } \\
\text { Norm }\end{array}$ & $\begin{array}{c}\text { Perceived } \\
\text { Behavioural } \\
\text { Control }\end{array}$ & $\begin{array}{c}\text { Perceived } \\
\text { Moral } \\
\text { Obligation }\end{array}$ & $\begin{array}{c}\text { Past } \\
\text { Behaviour }\end{array}$ \\
\hline Mean & 4.41 & 4.30 & 3.84 & 4.26 & 3.23 \\
Coefficient of Variation & 0.023 & 0.023 & 0.022 & 0.025 & 0.036 \\
Median & 0.005 & 0.005 & 0.006 & 0.006 & 0.011 \\
Mode & 4.5 & 4.18 & 3.92 & 4.33 & 3.5 \\
Standard Deviation & 5 & 4 & 4 & 4 & 3 \\
Skewness & 0.58 & 0.53 & 0.63 & 0.57 & 0.90 \\
Minimum & -1.053 & -0.292 & -0.480 & -0.562 & -0.293 \\
Maximum & 1 & 2.55 & 1.83 & 2.33 & 1 \\
Count & 5 & 5 & 5 & 5 & 4.5 \\
& 628 & 628 & 628 & 628 & 628 \\
\hline
\end{tabular}




\subsection{The Measurement Model}

\subsubsection{Construct Reliability and Validity}

In order to evaluate the construct reliability and validity of PLS-SEM measurement model, it is required to examine the convergent and discriminant validity of the indicators as well as the reliability of constructs. The convergent validity and composite reliability test the associations among indicators that belong to the same construct, thus ensuring that all questionnaire items measuring the same construct should be highly associated with each other. The internal reliability of the measurement model was tested by following a standard process based on the results of Cronbach's alpha and Fornell's measure of composite reliability [53].

Table 3. The measurement model.

\begin{tabular}{|c|c|c|c|c|c|}
\hline Constructs & Indicators & Factor Loading & Cronbach's Alpha & AVE & CR \\
\hline \multirow[t]{6}{*}{ Attitude (AT) } & AT1 & 0.856 & 0.930 & 0.743 & 0.945 \\
\hline & AT2 & 0.897 & & & \\
\hline & AT3 & 0.877 & & & \\
\hline & AT4 & 0.782 & & & \\
\hline & AT5 & 0.876 & & & \\
\hline & AT6 & 0.878 & & & \\
\hline \multirow[t]{11}{*}{ Subjective norm (SB) } & SB1a & 0.813 & 0.949 & 0.662 & 0.955 \\
\hline & SB1b & 0.840 & & & \\
\hline & SB2a & 0.811 & & & \\
\hline & SB2b & 0.849 & & & \\
\hline & SB3a & 0.768 & & & \\
\hline & SB3b & 0.863 & & & \\
\hline & SB4a & 0.756 & & & \\
\hline & SB4b & 0.839 & & & \\
\hline & SB5a & 0.805 & & & \\
\hline & SB5b & 0.838 & & & \\
\hline & SB6b & 0.755 & & & \\
\hline \multirow[t]{12}{*}{ Perceived behavioural control (PBC) } & PBC1a & 0.714 & 0.927 & 0.555 & 0.937 \\
\hline & PBC1b & 0.761 & & & \\
\hline & $\mathrm{PBC} 2 \mathrm{a}$ & 0.691 & & & \\
\hline & $\mathrm{PBC} 2 \mathrm{~b}$ & 0.754 & & & \\
\hline & PBC3a & 0.689 & & & \\
\hline & $\mathrm{PBC} 3 \mathrm{~b}$ & 0.693 & & & \\
\hline & PBC4a & 0.797 & & & \\
\hline & $\mathrm{PBC} 4 \mathrm{~b}$ & 0.744 & & & \\
\hline & PBC5a & 0.793 & & & \\
\hline & $\mathrm{PBC} 5 \mathrm{~b}$ & 0.755 & & & \\
\hline & PBC6a & 0.735 & & & \\
\hline & PBC6b & 0.799 & & & \\
\hline \multirow[t]{3}{*}{ Perceived moral obligation (PMO) } & PMO1 & 0.933 & 0.770 & 0.692 & 0.866 \\
\hline & PMO2 & 0.928 & & & \\
\hline & PMO3 & 0.585 & & & \\
\hline \multirow[t]{2}{*}{ Past behaviour (PRB) } & PRB1 & 0.933 & 0.858 & 0.876 & 0.934 \\
\hline & PRB2 & 0.939 & & & \\
\hline \multirow[t]{2}{*}{ Intention (AP) } & AP1 & 0.923 & 0.832 & 0.856 & 0.922 \\
\hline & $\mathrm{AP} 2$ & 0.928 & & & \\
\hline \multirow[t]{9}{*}{ Behaviour (WR) } & WR1 & 0.807 & 0.966 & 0.786 & 0.971 \\
\hline & WR2 & 0.864 & & & \\
\hline & WR3 & 0.850 & & & \\
\hline & WR4 & 0.931 & & & \\
\hline & WR5 & 0.936 & & & \\
\hline & WR6 & 0.894 & & & \\
\hline & WR7 & 0.923 & & & \\
\hline & WR8 & 0.877 & & & \\
\hline & WR9 & 0.889 & & & \\
\hline
\end{tabular}

AVE: average variance extracted; CR: composite reliability.

As we can see from Table 3, factor loadings for all constructs are more than the criteria value of 0.5 . Cronbach's alphas because all constructs exceed the criteria value of 0.7 , ranging from 0.770 to 0.966 , indicating a high degree of internal consistency. Likewise, all composite reliability (CR) 
values are more than 0.7 , ranging from 0.866 to 0.971 , demonstrating that all constructs are reliable. The average variance extracted (AVE) for all constructs are more than 0.5 , confirming that all constructs are established with satisfactory convergent validity.

\subsubsection{Discriminant Validity}

The test on discriminant validity of measured variables is performed to ensure that variables within different constructs are unrelated [54], that is, questionnaire items which measure different constructs should not be correlated. A guideline for evaluating discriminant validity is to check that the square root of AVE should be larger than the correlations between the construct and any other factors in the model [53]. As shown in Table 4, the values of the square root of AVE for the constructs in the diagonal are all greater than the correlations among the constructs that are below the diagonal. Hence, the results pass the discriminant validity test.

Table 4. Square root of AVE.

\begin{tabular}{cccccccc}
\hline Construct & Attitude & Behaviour & PBC & Intention & PMO & PRB & SB \\
\hline Attitude & $\mathbf{0 . 8 6 2}$ & & & & & & \\
Behaviour & 0.376 & $\mathbf{0 . 8 8 7}$ & & & & & \\
PBC & 0.495 & 0.620 & $\mathbf{0 . 7 4 5}$ & & & & \\
Intention & 0.274 & 0.480 & 0.485 & $\mathbf{0 . 9 2 5}$ & & & \\
PMO & 0.807 & 0.439 & 0.563 & 0.369 & $\mathbf{0 . 8 3 2}$ & & $\mathbf{0 . 9 3 6}$ \\
PRB & 0.257 & 0.498 & 0.543 & 0.666 & 0.318 & 0.346 & $\mathbf{0 . 8 1 3}$ \\
SB & 0.778 & 0.460 & 0.628 & 0.405 & 0.778 & \\
\hline
\end{tabular}

PBC: perceived behavioural control; PMO: perceived moral obligation, PRB: past behaviour; SB: subjective norm.

\subsection{The Structural Model}

We have established an acceptable structural model to detect the correlation between factors and intention, as well as the waste separation behaviour. As all the requirements are satisfactory, a bootstrapping process is conducted to show the significance of estimated path coefficients. The estimated path coefficients for the constructs are conveyed in a standardised form. The results of PLS estimation are shown in Figure 3 and Table 5 respectively.

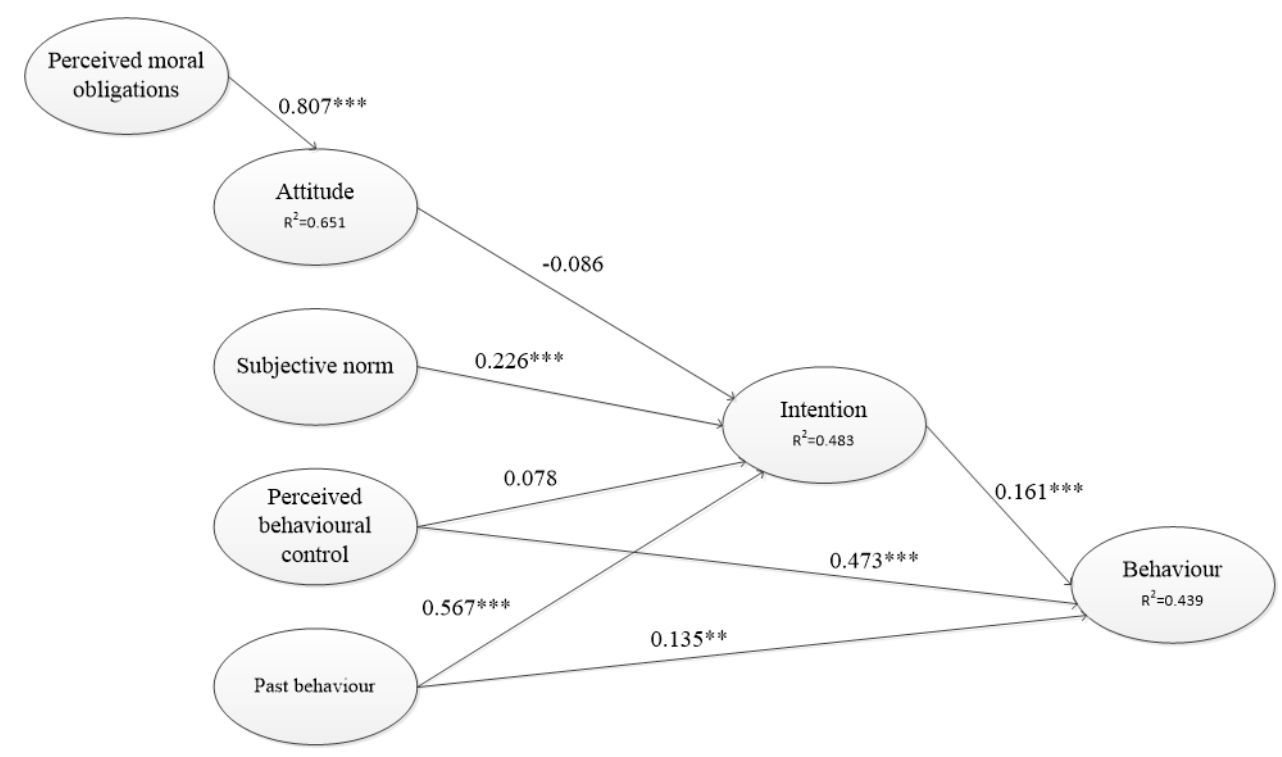

Figure 3. Partial least squares (PLS) estimation. * Significant at $p<0.05$, ** Significant at $p<0.01$, $* * *$ Significant at $p<0.001$. 
Table 5. Standardised path coefficients.

\begin{tabular}{clcc}
\hline Path/Hypothesis & & Path Coefficients $(\boldsymbol{\beta})$ & Result of Hypothesis Test \\
\hline Perceived moral obligations $\rightarrow$ Attitude & H1 & $0.807^{* * *}$ & Accept \\
Attitude $\rightarrow$ Intention & H2 & -0.086 & Reject \\
Subjective norm $\rightarrow$ Intention & H3 & $0.226^{* * *}$ & Accept \\
Perceived behavioural control $\rightarrow$ Intention & H4 & 0.078 & Reject \\
Perceived behavioural control $\rightarrow$ Behaviour & H5 & $0.473^{* * *}$ & Accept \\
Past behaviour $\rightarrow$ Intention & H6 & $0.567^{* * *}$ & Accept \\
Past behaviour $\rightarrow$ Behaviour & H7 & $0.135^{* *}$ & Accept \\
Intention $\rightarrow$ Behaviour & H8 & $0.161^{* * *}$ & Accept \\
\hline & $* p<0.05^{* *} p<0.01,{ }^{* * *} p<0.001$. &
\end{tabular}

As can be seen in Table 5, with respect to attitude, perceived moral obligations have a positive impact on attitude, confirming H1. Moreover, the construct accounts for $65 \%$ of the variance in attitude, indicating that a substantial amount of variance can be explained. Therefore, bringing emphasis on individuals' moral obligations can help to enhance individual's attitude in household waste separation behaviour.

With regard to intention, $\mathrm{H} 3, \mathrm{H} 6$ are supported while $\mathrm{H} 2$ and $\mathrm{H} 4$ are not. The results illustrate that waste separation intention can be explained by subjective norm and past behaviour; however, the impact of attitude and perceived behavioural control on intentions is not statistically significant at the level of 0.05 . The constructs account for $48 \%$ of the variance in intention, thus a moderate amount of variance can be explained by the constructs. In terms of waste separation behaviour, H5, H7 and $\mathrm{H} 8$ are confirmed. This conclusion shows that perceived behavioural control, past behaviour and intention all have a positive influence on waste separation behaviour. The constructs accounted for $44 \%$ of the variance in behaviour, illustrating that a moderate amount of variance can be explained by the constructs.

The results also indicate that past behaviour is the strongest predictor of waste separation intention and behaviour, with the largest estimated path coefficient of all TPB constructs in this study. This conclusion is in line with the results proposed by Pakpour et al. [1], indicating that past behaviour can significantly predict household waste behaviour. In other words, people tend to form intentions that are accordant with past behaviour, and then captivate those positive intentions to carry out that behaviour in the future [55].

Perceived behavioural control has a positively significant effect on behaviour, which reflects how an individual with strong perception of behavioural control would perform in waste separation [56], compared with an insignificant influence on intention, which is not surprising as there is evidence in the context of waste separation that an individual's opportunity and ability do not necessarily convert into motivational influence of control on behavioural intention [57].

Subjective norm is also considered as another significant predictor of waste separation intention, indicating that an individual's positive interpretation of pressure from peers influences their intention. It is also consistent with previous study showing that subjective norms have a positive effect on pro-environmental behaviour [58]. When an individual is unsure of the correct action to take, their individual responsibilities would be drawn to the inference of others' behaviours [59]. This reveals that someone's willingness to carry out waste separation can be dominated by their beliefs about others' behaviours. Hence, an individual will then act responsibly based on their certainty towards other's behaviour.

Additionally, this study shows that intention can positively influence behaviour, indicating that increasing intention of waste separation behaviour can highly boost waste separation behaviour. This is also in line with a previous study [57] which have explained that residents who hold stronger intention are more likely to carry out waste separation than those who hold weaker intention.

The results also prove that an individual's attitude is insignificant towards intention in carrying out waste separation. This is not consistent with other related researches that claimed attitude could 
significantly predict behavioural intentions [1,12], which is possible because of the reason that attitude is usually operationalised by asking how an individual feels the performance of an action. Even when the results of measurement reflect the affective component of attitude, it does not pay sufficient attention to the process of executing an action. Hence, a positive attitude of performing an act in this study cannot end up with a positive intention.

\section{Discussion}

It is worth noting that the demographic factors have often been regarded as key determinants to predict pro-environmental behaviour of residents, whereas previous studies have seldom considered their influence carefully. Iosif Botetzagiasa et al. added demographic factors as independent variables to the TPB model in the context of recycling, but they found the correlation between pro-environmental behaviour and demographic factors was insignificant [37]. Interestingly, Pakpour et al. found that only age and gender were significant predictors of household waste separating behaviours [1]. The contradictory findings drive us to refocus on the influences of demographic factors and reconsider their moderating effects rather than the direct effects on endogenous variables. This can help us understand the applicability and diversity of the extended TPB model in populations with various social-demographic features in great detail and be realised by multiple-group PLS. Notably, we did not examine the moderating effect of education level of residents since the correlation result between education and various TPB constructs is not significant. This echoes the previous research that states an inconclusive result regarding the relationship between the education level and waste separation behaviour. For instance, the studies in different cultural contexts such as America, Spain or Iran have revealed that the improvement of individual's education does not necessarily lead to a stronger intention nor better performance in household waste separation $[1,6,60]$. One possible reason for this is that household waste separation requires specific pro-environmental knowledge rather than general knowledge received from degree education programs.

With respect to perceived policy effectiveness, one research study has proved that the environmental policy could be a useful tool for promoting pro-environmental behaviours [38]. Wan et al. proposed a model that integrates TPB and the Norm Activation Model (NAM) to predict recycling behaviours and added perceived policy effectiveness into the model as a moderating variable. Their results presented the perceived policy effectiveness, which played a negative moderating role between subject norm and recycling intention [40]. However, the function of perceived policy effectiveness may not be fully discussed towards waste separation behaviours. Therefore, moderating the effect of perceived policy effectiveness on the extended TPB model is another focus of this study.

\subsection{Spearman's Rho Correlation}

A Spearman's rho correlation analysis was performed to evaluate the relationship between demographic factors and independent variables. As can be seen from the results in Table 6, there is a small significance between gender and subjective norm, moderate significance between age, perceived behavioural control and past behaviour as well as moderate significance between income, attitude, subjective norm and perceived moral obligation. Besides, the perceived policy effectiveness has significant correlation with all independent variables. Accordingly, gender, age, income and perceived policy effectiveness are selected to perform in PLS-SEM in order to determine the differences effects of demographic characteristics on waste separation behaviour performance. 
Table 6. Spearman's rho correlation matrix (sample size of 628).

\begin{tabular}{ccccccc}
\hline \multicolumn{2}{c}{ Spearman's Rho } & Attitude & SB $^{\mathbf{a}}$ & PBC $^{\mathbf{a}}$ & PMO $^{\mathbf{a}}$ & PRB $^{\mathbf{a}}$ \\
\hline \multirow{2}{*}{ Gender } & CC $^{\text {a }}$ & 0.062 & $0.088^{*}$ & 0.053 & 0.072 & -0.055 \\
& Sig. & & & \\
\multirow{2}{*}{ Age } & 0.119 & 0.028 & 0.187 & 0.070 & 0.166 \\
& CC & 0.010 & 0.054 & $0.165^{* *}$ & 0.038 & $0.148^{* *}$ \\
& Sig. & 0.796 & 0.177 & 0.000 & 0.346 & 0.000 \\
\multirow{2}{*}{ Income } & CC & $0.157^{* *}$ & $0.124^{* *}$ & 0.069 & $0.150^{* *}$ & 0.032 \\
& Sig. & 0.000 & 0.002 & 0.083 & 0.000 & 0.423 \\
\hline \multirow{2}{*}{ PPE $^{\text {a }}$} & CC & $0.564^{* *}$ & $0.665^{*}$ & $0.650^{* *}$ & $0.620^{* *}$ & $0.381^{* *}$ \\
& Sig. & 0.000 & 0.000 & 0.000 & 0.000 & 0.000 \\
\hline
\end{tabular}

a SB means subjective norm; PBC means perceived behavioural control; PMO means perceived moral obligation; PRB means past behaviour; PPE means perceived policy effectiveness; CC means correlation coefficient; ${ }^{b}$ 2-tailed significance; * Correlation is significant at the 0.05 level (2-tailed), ${ }^{* *}$ Correlation is significant at the 0.01 level (2-tailed).

\subsection{Gender}

As shown in the Table 7, the results of the model path are separated by the different in genders, that is, gender has a moderating effect on separating intention and behaviour, which is consistent with the study of Botetzagias [37]. The relationships between moral obligations and attitude (H1), subjective norm and intention (H3), perceived behavioural control and behaviour (H5), past behaviour and intention (H6) as well as intention and behaviour (H8) are all significant for both males and females. However, the path from perceived behavioural control towards intention (H4) and path from past behaviour towards behaviour (H7) are only significant for males. This simply means that, compared with females, males reflect a stronger motivational influence of perceived control on behaviour intention. In particular, the result of $\mathrm{H7}$ demonstrates that males tend to more easily adhere to their own habits. These results indicate the enhancement of perceived behavioural control and behaviour habits plays a more remarkable role for males performing separating action, and the achievement of potential efficacy of waste separation schemes can be achieved. Accordingly, it is suggested that targeting males, an effective way to promote waste separation behaviour, involves a higher, more intensive publicity regarding separating knowledge and values, and the more sufficient and convenient collection facilities and services.

Table 7. Standardised path coefficients for gender.

\begin{tabular}{ccccc}
\hline \multirow{2}{*}{ Path/Hypothesis } & & \multicolumn{2}{c}{ Path Coefficients $(\boldsymbol{\beta})$} & \multirow{2}{*}{ Significance } \\
\cline { 3 - 4 } & & Male & Female & \\
\hline PMO $\rightarrow$ Attitude & H1 & $0.785^{* * *}$ & $0.834^{* * *}$ & Both \\
Attitude $\rightarrow$ Intention & H2 & -0.137 & -0.051 & Both \\
Subjective norm $\rightarrow$ Intention & H3 & $0.209^{*}$ & $0.226^{* *}$ & Both \\
PBC $\rightarrow$ Intention & H4 & $0.166^{*}$ & 0.016 & Males \\
PBC $\rightarrow$ Behaviour & H5 & $0.491^{* * *}$ & $0.448^{* * *}$ & Both \\
Past behaviour $\rightarrow$ Intention & H6 & $0.552^{* * *}$ & $0.588^{* * *}$ & Both \\
Past behaviour $\rightarrow$ Behaviour & H7 & $0.178^{* *}$ & 0.124 & Males \\
Intention $\rightarrow$ Behaviour & H8 & $0.146^{*}$ & $0.154^{*}$ & Both \\
\hline
\end{tabular}

PMO: perceived moral obligation; PBC: perceived behavioural control. ${ }^{*} p<0.05,{ }^{* *} p<0.01,{ }^{* * *} p<0.001$.

\subsection{Age}

The age group is classified based on the extreme tails of the respondents' age in this study. The subgroup of young adult is at ages ranging from 19 to 29 years old, compared with 30-50 in the middle-aged group and 51-89 in the senior-aged group. As shown in Table 8, the results of the model 
path are different among subgroups of age, that is, the factor of age has an effect on the extended TPB model. To be precise, for all three subgroups, the path from perceived moral obligations towards attitude (H1), perceived behavioural control towards behaviour (H5) and past behaviour towards intention (H6) are significant, whereas the path of attitude towards intention (H2) is not.

Table 8. Standardized path coefficients for age.

\begin{tabular}{cccccc}
\hline \multirow{2}{*}{ Path/Hypothesis } & \multicolumn{3}{c}{ Path Coefficients $(\beta)$} & \multirow{2}{*}{ Significance } \\
\cline { 3 - 5 } & & Young & Middle & Senior & \\
\hline PMO $\rightarrow$ Attitude & H1 & $0.817^{* * *}$ & $0.796^{* * *}$ & $0.844^{* * *}$ & All \\
Attitude $\rightarrow$ Intention & H2 & -0.046 & -0.066 & -0.213 & All \\
Subjective norm $\rightarrow$ Intention & H3 & 0.196 & $0.228^{* *}$ & 0.260 & Middle \\
PBC $\rightarrow$ Intention & H4 & $0.194^{*}$ & 0.007 & 0.178 & Young \\
PBC $\rightarrow$ Behaviour & H5 & $0.318^{* *}$ & $0.489^{* * *}$ & $0.541^{* * *}$ & All \\
Past behaviour $\rightarrow$ Intention & H6 & $0.555^{* * *}$ & $0.603^{* * *}$ & $0.477^{* * *}$ & All \\
Past behaviour $\rightarrow$ Behaviour & H7 & 0.093 & $0.130^{*}$ & 0.133 & Middle \\
Intention $\rightarrow$ Behaviour & H8 & $0.303^{* *}$ & $0.133^{*}$ & 0.155 & Young and middle \\
\hline
\end{tabular}

PMO: perceived moral obligation; PBC: perceived behavioural control. ${ }^{*} p<0.05,{ }^{* *} p<0.01,{ }^{* * *} p<0.001$.

Notably, the path between subjective norm and intention (H3) and the path between past behaviour and behaviour (H7) are significant for the middle-aged group alone. The result of H3 indicates that the intention of middle-aged adults towards behaving in a more eco-friendly way is affected by critical social referent groups around them, which might be due to the interaction with family or the motivation to be an example for their family members, especially children, and/or the consideration of the health situation of the whole family. This is fundamentally consistent with the existing study [61], which stated that adults with children would perform much better in pro-environmental programs. In addition, the result about $\mathrm{H} 7$ demonstrates that the middle-aged adults tend to follow their own past experience of performing the waste separation behaviours.

Particularly, the result illustrates that perceived behavioural control has a significantly positive influence on intention (H4) for the young-aged subgroup alone. Young adults tend to have higher levels of volitional control when they intend to separate the waste; therefore, the adequate provision of waste collection and separation facilities distributed at most convenient places for young adults might be more effective to promote their effort to perform this desired action. The path between intention and behaviour (H8) is only significant in the young- and middle-aged group. This conclusion demonstrates an intention-behaviour gap is more likely to occur in the senior-aged group, in other words, older adults who hold favourable intention towards waste behaviour do not necessarily perform an action in the end.

\subsection{Income}

The income group is classified based on the extreme tails of the respondents' family income level in this study. The household monthly revenue in the low-income group is below CNY 5000, compared with the ranges from CNY 5000 to CNY 15,000 in the middle-income group whereas the high income level is more than CNY 15,000. As shown in Table 9, the results of the model path are different in the three subgroups Thus, the household income level also has a moderating effect on the endogenous constructs of the extended TPB model, which is consistent with the study of [62]. For all of the three subgroups, the paths between perceived moral obligations and attitude (H1), perceived behavioural control towards behaviour (H5) and past behaviour towards intention (H6) are all statistically significant, while the path between perceived behavioural control and intention (H4) is insignificant. The paths between attitude and intention (H2), subjective norm and intention (H3) and past behaviour and behaviour (H7) are significant for middle-income level alone. The result of $\mathrm{H} 2$, especially, indicates that the attitude of householders at middle-income level has a negative influence on their intention. For middle-income respondents, the average value of attitude is 4.38 and average 
value of intention is 3.74, which further elaborates the descending trend of the relationship between these two factors. The unexpected finding might be explained by the idea that the middle-income level group are more vulnerable to perceived high social pressure than other income levels due to a main obligation to the family while trying to do well in jobs. It will be difficult for the middle-income level to notice the environmental issue and at the same time to be willing to perform an eco-friendly action even though they have a strong positive attitude to the waste separation. The results of $\mathrm{H} 3$ and H7 demonstrate that, for middle-income level people, the intention depends on what they perceived as normal behaviour, and the behaviour is positively affected by their habits. Nevertheless, we find that only high-income level resulted in a lack of significance for intention towards behaviour (H8), indicating that intention of the low and middle income level people may promote behaviour but there is an intention-behaviour gap in the high income level group. One possible explanation from the study proposed by Czajkowski et al. is that they explained lower income people implement the intention to the action of sorting waste because they believe that recycling can eventually help to save money [63].

Table 9. Standardized path coefficients for household income.

\begin{tabular}{cccccc}
\hline Path/Hypothesis & & \multicolumn{3}{c}{ Path Coefficients $(\beta)$} & \multirow{2}{*}{ Significance } \\
\cline { 3 - 5 } & & Low Income & Middle Income & High Income & All \\
PMO $\rightarrow$ Attitude & H1 & $0.783^{* * *}$ & $0.810^{* * *}$ & $0.828^{* * *}$ & Middle income \\
Attitude $\rightarrow$ Intention & H2 & 0.027 & $-0.194^{* *}$ & 0.133 & Middle income \\
Subjective norm $\rightarrow$ Intention & H3 & 0.092 & $0.304^{* * *}$ & 0.143 & All \\
PBC $\rightarrow$ Intention & H4 & 0.175 & 0.057 & 0.026 & All \\
PBC $\rightarrow$ Behaviour & H5 & $0.491^{* * *}$ & $0.492^{* * *}$ & $0.447^{* *}$ & All \\
Past behaviour $\rightarrow$ Intention & H6 & $0.585^{* * *}$ & $0.563^{* *}$ & $0.595^{* * *}$ & Middle income \\
Past behaviour $\rightarrow$ Behaviour & H7 & $0.016^{* *}$ & $0.174^{* *}$ & 0.119 & Low and middle income \\
Intention $\rightarrow$ Behaviour & H8 & $0.363^{* * *}$ & $0.163^{* *}$ & 0.065 & L
\end{tabular}

PMO: means perceived moral obligation; PBC: perceived behavioural control. ${ }^{*} p<0.05,{ }^{* *} p<0.01,{ }^{* * *} p<0.001$.

\subsection{Perceived Policy Effectiveness (PPE)}

Table 10 presents the multi-group effects in two groups: the low perceived policy effectiveness group $(<3.8)$ and high perceived policy effectiveness group $(\geq 3.8)$, distinguished by K-means. The results show that the path from attitude towards intention (H2) is insignificant for both low and high PPE groups, while the paths from perceived moral obligations towards attitude (H1), past behaviour towards intention (H6) and intention towards behaviour (H8) are significant for both groups. Interestingly, the paths from perceived behavioural control towards behaviour (H5) and past behaviour towards behaviour (H7) are only significant for the high PPE group, which indicates that residents who have high level of perceived policy effectiveness may facilitate the translation of perceived behavioural control into waste separation behaviour. Besides, the path from subjective norm towards intention (H3) is also significant for the high PPE group. This result demonstrates that, between subject norm and intention, perceived policy effectiveness plays a positive moderating role, which is in contrast to the study of Wan et al. [40]. Particularly, the result illustrates that perceived behavioural control has a significantly positive influence on intention (H4) for the low PPE group alone. It shows that the effect of perceived behavioural control only surfaces when the score of perceived policy effectiveness is at a low level, which illustrates that if a government does not effectively implement their policies in terms of motivating waste separation behaviour, the perceived behaviour control will strongly influence one's intention to segregate waste. 
Table 10. Standardised path coefficients for perceived policy effectiveness (PPE).

\begin{tabular}{ccccc}
\hline Path/Hypothesis & & \multicolumn{2}{c}{ Path Coefficients $(\beta)$} & \multirow{2}{*}{ Significance } \\
\cline { 3 - 4 } & & Low PPE & High PPE & \\
\hline PMO $\rightarrow$ Attitude & $\mathrm{H} 1$ & $0.791^{* * *}$ & $0.790^{* * *}$ & Both \\
Attitude $\rightarrow$ Intention & $\mathrm{H} 2$ & -0.108 & -0.088 & Both \\
Subjective norm $\rightarrow$ Intention & $\mathrm{H} 3$ & 0.162 & $0.199^{* * *}$ & High PPE \\
$\mathrm{PBC} \rightarrow$ Intention & $\mathrm{H} 4$ & $0.283^{*}$ & 0.020 & Low PPE \\
$\mathrm{PBC} \rightarrow$ Behaviour & $\mathrm{H} 5$ & -0.176 & $0.478^{* * *}$ & High PPE \\
Past behaviour $\rightarrow$ Intention & $\mathrm{H} 6$ & $0.507^{* * *}$ & $0.573^{* * *}$ & Both \\
Past behaviour $\rightarrow$ Behaviour & $\mathrm{H} 7$ & -0.076 & $0.152^{* *}$ & High PPE \\
Intention $\rightarrow$ Behaviour & $\mathrm{H} 8$ & $0.635^{* * *}$ & $0.128^{* *}$ & Both \\
\hline
\end{tabular}

PMO: perceived moral obligation; PBC: perceived behavioural control. ${ }^{*} p<0.05,{ }^{* *} p<0.01,{ }^{* * *} p<0.001$.

\subsection{From Demographic Factors to Waste Separation Behaviour}

Targeting further analysis on the ability of demographic factors towards predicting resident waste separating behaviour, we are particularly interested in whether the accurate prediction of residents' behaviour could be made by collecting detailed demographic data for the subject households, when a wide range survey or field experiment is not attainable. This interest also comes with the idea that the predicted results are able to establish links between demographic profiles and behaviour for policy making purpose in terms of urban management. However, to our best knowledge, there is still no discussion on this issue in the field of waste separation or even pro-environmental behaviour. Therefore, this research tested whether using the demographic profile could ideally predict one's waste separation behaviour based on multiple Machine Learning (ML) models (see more detailed explanation of the models in Appendix B). The ML models are essentially an approach for "optimizing a performance criterion using example data and past experience" through machine learning algorithm [64].

We selected the waste separation behaviour of discarded and easy-open cans as an example. The response of "never collect at all" and "seldom collect" from the questionnaire scale are considered as "do not perform the desired behaviour" (labelled as category "not behave"), while the response of "collect sometimes", "collect regularly" and "always collect" are considered as "perform the desired behaviour" (labelled as category "behave"). All of the demographic data is used as the training set to make predictions about residents' behaviour. In addition, by using Rattle package of $R$, all of the machine learning models including Decision Tree Model, Ada Boost Model, Random Forest Model, Support Vector Machine Model, Linear Model and Neural Net Model are performed in this section.

As shown in Table 11, with respect to the overall accuracy, the Linear Model is better than any other models in terms of accuracy. All six models have acceptable prediction accuracy of performing the desired behaviour, while their performance on predicting "do not perform the desired behaviour" is inferior. The results show that the Support Vector Machine Model is the most accurate prediction model for predicting "perform the desired behaviour", but it fails when predicting "do not perform the desired behaviour". The finding also presents that when predicting "perform the desired behaviour", the Linear Model is better than the Neural Net Model. This means that, if the user wants to catch the category" 1 ", user can get the high accurate prediction using the Linear Model. For the accuracy of predicting "do not perform the desired behaviour", the Neural Net Model is better than the other five models. However, the accuracy for the Neural Net Model is only 17\%, indicating that it is not accurate enough for the prediction. For the future application, we need to collect a more detailed demographic profile for the subject household in order to train the model to get the accurate prediction of residents' behaviour. In conclusion, users need to properly choose the model to predict based on their purpose. 
Table 11. The performance of each model.

\begin{tabular}{cccc}
\hline Model & $\begin{array}{c}\text { Accuracy of All } \\
\text { Responses }\end{array}$ & $\begin{array}{c}\text { Accuracy of Category } \\
\text { "Behave" }\end{array}$ & $\begin{array}{c}\text { Accuracy of Category } \\
\text { "Not Behave" }\end{array}$ \\
\hline Decision Tree & $71 \%$ & $94 \%$ & $0 \%$ \\
Ada Boost & $69 \%$ & $92 \%$ & $0 \%$ \\
Random Forest & $72 \%$ & $92 \%$ & $13 \%$ \\
Support Vector Machine & $75 \%$ & $100 \%$ & $0 \%$ \\
Linear & $76 \%$ & $99 \%$ & $9 \%$ \\
Neural Net & $73 \%$ & $92 \%$ & $17 \%$ \\
\hline
\end{tabular}

Note: All responses include both category "behave" and category "not behave".

\section{Conclusions}

Based on the socio-psychological theories predicting human pro-environmental behaviours, this study explored and assessed the psychological and demographic determinants of waste separation intention and behaviour. The empirical findings based on a sample of residents in Hangzhou provide abundant valuable evidences on the application of TPB for predicting and understanding residents' intention and behaviour towards waste separation.

The demographic characteristics and perceived policy effectiveness are validated to moderate the size and significance of the effect of all the independent variables in the extended TPB model through the multiple-group PLS. This study also demonstrated that the perceived behavioural control positively affects intention only for males and young adults. Besides, for middle-aged adults and middle-income groups, the subjective norm has a positive influence on the intention. Moreover, the past behaviour of males, middle-aged adults and middle-income groups positively affect their own waste separation behaviour. Interestingly, for young and middle-aged as well as low- and middle-income adults, the intention has a direct effect on behaviour, and this result does not show any difference in gender. This study also finds that a high level of perceived policy effectiveness may facilitate the translation of perceived behavioural control into waste separation behaviour. In addition, between subject norm and intention, perceived policy effectiveness plays a positive moderating role. In the context of these results, the local government and environmental organisations ought to make targeted policies that can work well for different kinds of people in terms of their gender, age and income, to further evoke household waste separation behaviours. For example, promotion of waste separation can be implemented among young people in schools which can help influence their families. Additionally, local government should also pay more attention to facilitate the waste separation behaviour of the older adults and high-income groups. In addition, the study also finds that, when it is not possible to conduct a wide range survey or field experiment accurate prediction of residents' behaviour could be made through machine learning models, by collecting more detailed demographic data for the subject household.

To the best of our knowledge, this study has four crucially theoretical contributions. First, we expanded the structural model of TPB constructs by incorporating both perceived moral obligation and past behaviour, in order to accommodate other potential determinants and to predict the waste separating behaviour more accurately. The explanatory power of these new variables was also validated. Second, the past behaviour represents the strongest effect on household waste separation intention and behaviour, manifesting the importance of habit formation in predicting the separating behaviours of residents in the Eastern China. Third, different from previous researches, this paper focuses on the moderating effects of demographic factors and perceived policy effectiveness on separating attitude, intention and behaviour rather than treating them as control variables, which allow us to explore and discuss the changing status of the TPB model in the populations with differentiated gender, age and income. Last but not least, we demonstrated the accurate prediction of residents' behaviour through machine learning models by collecting detailed demographic data for the subject 
household. This method provides possibilities to forecast residential waste separating behaviour when conducting a wide range survey or field experiment is not available.

As the expanded TPB constructs can predict household waste separation behaviour, it offers promising results that might help to develop effective green campaigns not only in similar cities in China, but also in other regions where household waste separation behaviours are rarely performed. Based on a community-based questionnaire survey with a large sample size in Hangzhou, the results have shown that perceived behavioural control, past behaviour and intention are the predictors of household waste separation behaviour. Moreover, an individual's attitude can be explained by one's perceived moral obligation, whereas waste separation intention is only affected by subjective norm and past behaviour. The waste separation behaviour is significantly influenced by perceived behavioural control, past behaviour and intention, among which an individual's past behaviour is the strongest predictor for waste separation behaviour. In the future, policy makers should focus on residents' habit forming by providing convenient ways to separate waste and undertake intensive information campaign Examples of these policies are: installing adequate separation bins, developing mass mobilisation and community education, encouraging recycling companies, informal recycling system consisting of waste pickers, itinerant buyers, traders in waste materials and non-registered small-scale enterprises, which are suggested to largely influence the efficiency of household waste management in developing countries [8,10,65-69]. Other sectors should participate in the urban household waste management. Implementing mandatory regulations is necessary and beneficial to help residents form their behavioural habits for separating waste.

This study investigated household waste separation behaviour in a representative area in Hangzhou, and derived several policy implications that are potentially meaningful for similar areas in China with a careful examination. One limitation of this paper is an analysis based on a sample of 628 valid questionnaires that is relatively small to represent the total population of a city. Having noted this limitation, we adopted a powerful analytical method PLS with bootstrapping function that increases the significance of results regardless of sample size. In addition, using a small sample size (300 residents or fewer) to represent household waste behaviour in a region and/or a city has also been shown to have strong effectiveness and validation in many previous studies $[5,21,70]$. However, we do recognise that the various societal and cultural factors in China such as the economic development, institution systems, and civilisation levels may influence household waste separating behaviours and make the interpretation of separating behaviour more complicated and elusive in different contexts. Therefore, for future application of the extended TPB model towards household waste separation behaviour of the Chinese population, more investigations across different cultures and based on a larger sample should be further tested and confirm these findings. Additionally, this research did not consider the sale of recyclable materials as a determinant in waste separation behaviour, which might have some effects on the behaviour change with an economic incentive. Therefore, future studies could also enrich the behaviour model by testing the effect of monetary motivation in waste separation behaviours.

Acknowledgments: The authors would also thank research assistant, Shandy Toh Qian Hui, for her work in the compilation of literature review and the preparation of data analysis. The study is partially sponsored by the Ministry of Education, Singapore via the Tier 1 research program administered by the National University of Singapore (R-296-000-151-133), by the National Research Foundation (NRF) via the Green Buildings Innovation Cluster (GBIC), administered by Building and Construction Authority (BCA) (R-296-000-168-490) and by the National Social Science Foundation of China (15BZZ066). The information and views set out in this article are those of the authors and do not necessarily reflect the official opinion of the grantors.

Author Contributions: This article was originally conceived and designed by Lin Xu and Yujie Lu, with data collection managed by Lin Xu and Maoliang Ling. An initial draft was prepared by Yujie Lu and Meng Shen, and was later revised by all of the authors. All authors have read and approved the final manuscript.

Conflicts of Interest: The authors declare no conflict of interest. 


\section{Appendix A Survey Questions}

Attitude

AT1 Waste separation helps to protect the environment and conserve resources, we should do it ${ }^{\text {a }}$

AT2 I am very interested in garbage separation and it allows me to have fulfilment, we should do it ${ }^{\text {a }}$

AT3 Waste separation shows personal hygiene performance, we should do it a

AT4 Separated recyclable waste can be sold to receive remuneration, we should do it a

AT5 I can set an example for children by carrying out waste separation, we should do it a

AT6 Waste separation can help country to reduce pollution control costs, we should do it a

Subjective norms

SB1a Do your family support you in performing household waste separation ${ }^{b}$

SB1b If your family encourage you to carry out waste separation, are you willing to listen to their advice? ${ }^{\mathrm{C}}$

SB2a Do your friends or colleagues support you in performing waste separation? ${ }^{b}$

$\mathrm{SB} 2 \mathrm{~b}$ If your friend or colleague encourages you in carrying out waste separation, are you willing to listen to their advice? ${ }^{\mathrm{c}}$

SB3a Do your neighbours support you in performing waste separation? $b$

SB3b If your neighbours encourage you in carrying out waste separation, are you willing to listen to their advice? $^{\mathrm{c}}$

SB4a Do your government and community support you in performing waste separation? ${ }^{b}$

SB4b If your government and community encourage you in carrying out waste separation, are you willing to listen to their advice? ${ }^{\mathrm{c}}$

SB5a Do your environmental organizations support you in performing waste separation? ${ }^{b}$

$\mathrm{SB} 5 \mathrm{~b}$ If your environmental organizations encourage you in carrying out waste separation, are you willing to listen to their advice? ${ }^{\mathrm{c}}$

SB6b Would you like to listen to environmental protection programs, news press call to perform waste separation? ${ }^{\mathrm{c}}$

Perceived behavioural control

PBC1a Do you have enough time to carry out waste separation? ${ }^{d}$

$\mathrm{PBC} 1 \mathrm{~b}$ If you do not have enough time, will you still carry out waste separation? ${ }^{\mathrm{e}}$

PBC2a Do your home has enough space for storing of sorted waste? ${ }^{f}$

$\mathrm{PBC} 2 \mathrm{~b}$ If your home does not have sufficient space for storing of sorted waste, will you still carry out waste separation? ${ }^{\text {e }}$

PBC3a Do your government or community provides you with complete facilities for waste separation (such as separation bags, sorting bins)? $\mathrm{g}$

PBC3b If your government or community do not provide you with complete facilities for waste separation, will you still carry out waste separation? ${ }^{\mathrm{e}}$

PBC4a Do you know how waste is separated into different categories and which of those can be recycled? ${ }^{\mathrm{h}}$

PBC4b If you do not know how to separate waste into different categories, will you still carry out waste separation? ${ }^{\mathrm{e}}$

PBC5a Do you know which recycling bins those sorted waste should be put into? ${ }^{\mathrm{h}}$

$\mathrm{PBC} 5 \mathrm{~b}$ If you do not know how those sorted waste should be put into which recycling bins, will you still carry out waste separation? ${ }^{\mathrm{e}}$

PBC6a Is your home convenient to carry out waste separation? (such as recycling bins are too far from your house that resulted in inconvenience) ${ }^{i}$

PBC6b If your home is inconvenient, will you still carry out waste separation? ${ }^{\mathrm{e}}$ 
Perceived moral obligations

PMO1 Waste separation is an ethical behaviour to protect the ecological environment, everyone has a duty to do so ${ }^{\text {a }}$

PMO2 Waste separation is a thrifty ethical behaviour, everyone has an obligation to do so ${ }^{\text {a }}$

PMO3 During unsupervised times, will you feel ashamed that waste is thrown into trash without going through waste separation? ${ }^{j}$

Intention to Recycle

AP1 Starting from next week, will you prepare to carry out waste separation? ${ }^{k}$

AP2 During the next week, how many days are you willing to carry out waste separation? ${ }^{1}$

Separating Behaviour

WR1 Waste paper/waste paper board ${ }^{m}$

WR2 Discarded batteries, electronic equipment ${ }^{m}$

WR3 Leftover food, kitchen waste ${ }^{m}$

WR4 Discarded plastic bottles $\mathrm{m}$

WR5 Discarded cans, easy-open cans ${ }^{m}$

WR6 Discarded metal ${ }^{m}$

WR7 Renewable plastics ${ }^{\mathrm{m}}$

WR8 Discarded glass bottles $\mathrm{m}$

WR9 Discarded clothing, fabrics $\mathrm{m}$

Demographic

Gender; Age; Family income; Highest Education Level; Occupation

Perceived Policy Effectiveness

PPE1 Government attaches great importance to waste separation problem, and has been actively advocating efforts to get residents involved in the daily waste separation. ${ }^{\text {a }}$

PPE2 Government and communities provide a scientific, effective and concise waste separation standard. ${ }^{\text {a }}$

PPE3 Government, community-driven campaigns can clearly explain the benefits and importance of waste separation. $^{\text {a }}$

PPE4 Government, community-driven separation campaigns can effectively improve waste separation awareness of residents. ${ }^{a}$

PPE5 The waste separation bins provided by government provides a favourable and convenient environment for residents. ${ }^{\text {a }}$

Note: The scale of measurement (from low to high) is described as follows.

a Strongly disagree, Disagree, Not necessarily, Agree, Strongly agree.

b Strongly unsupportive, Unsupportive, Not sure, Supportive, Strongly supportive.

c Very unwilling, Unwilling, Not necessarily, Willing, Very willing.

d Totally no time, Do not really have time, Depends on situation, Often have time, Always have time.

e Definitely will not, Will not, Depends on situation, Will, Definitely will.

f Totally no space, Do not really have space, Depends on situation, Often have space, Always have space.

g No facilities at all, Little facilities, Not sure, Almost complete facilities, Complete facilities.

h Completely do not know, Do not know, Knows a little, Knows, Completely knows.

i Very inconvenient, Inconvenient, Depends on situation, Convenient, Very convenient.

j Very not ashamed, Not ashamed, Depends on situation, Ashamed, Very ashamed.

k Totally impossible; Almost impossible; Depends on situation; Very likely; Definitely will.

$1 \quad$; 1 -2 days; 3-4 days; 5-6 days; everyday.

m Never collect at all; Seldom collect; Collect sometimes; Collect regularly; Always collect. 


\section{Appendix B Description of Each Machine Learning Model and the Original Prediction Results}

\section{Appendix B.1 Decision Trees Model}

One of the classic machine learning techniques widely deployed in data mining is the decision tree induction [71]. Using a simple algorithm with tree structure to represent the model, the approach has been proven to be truly effective. The "rpart" function of Rattle is used to perform a decision tree model according to a list of rules from conversion of the decision tree into a list of rules [72]. The original outputs of Decision Tree prediction for this study are shown in Table A1.

Table A1. The result of decision tree prediction.

\begin{tabular}{ccccc}
\hline Actual & Predicted & $\mathbf{0}$ & $\mathbf{1}$ & Error \\
\hline 0 & 0.00 & 0.24 & 1.00 \\
1 & 0.04 & 0.71 & 0.06 \\
\hline
\end{tabular}

Appendix B.2 Adaptive Boosting Model

Compared to Decision Tree, Adaptive Boosting (known as AdaBoot) combines various learning algorithms to enhance the performance of prediction [73]. In AdaBoot model, the training set (Equation (A1)) is required to be identified. The maximum number of iterations and the weight distribution are both required to be initialized in AdaBoot. By grouping the output from the learning algorithms, "weak learners", into a weighted sum F(x) that displays the final voted classifier [74], the original results of AdaBoot prediction is shown in Table A2.

$$
F_{T}(x)=\sum_{t=1}^{T} f_{t}(x)
$$

Table A2. The result of AdaBoot prediction.

\begin{tabular}{ccccc}
\hline Actual & Predicted & $\mathbf{0}$ & $\mathbf{1}$ & Error \\
\hline 0 & & 0.00 & 0.24 & 1.00 \\
1 & 0.06 & 0.69 & 0.08 \\
\hline
\end{tabular}

\section{Appendix B.3 Random Forests Model}

Random Forests Model is an ensemble learning method of the classification of dependent variables by constructing multiple decision trees during the training period [75]. To get a more accurate and stable prediction $\mathrm{p}(\mathrm{c} \mid \mathrm{f})$ through maximum voting, the algorithm amalgamate several decision trees from inputting the variables Feature (f) that build multiple decision trees Tree $t_{n}, \cdots$, Tree $t_{n}$. The architecture of the Random Forests Model is shown in Figure A1. Table A3 presents the original results of Random Forests prediction.

Table A3. The result of random forests prediction.

\begin{tabular}{ccccc}
\hline Actual & Predicted & $\mathbf{0}$ & $\mathbf{1}$ & Error \\
\cline { 1 - 3 } 0 & & 0.03 & 0.21 & 0.87 \\
1 & 0.06 & 0.69 & 0.08 \\
\hline
\end{tabular}




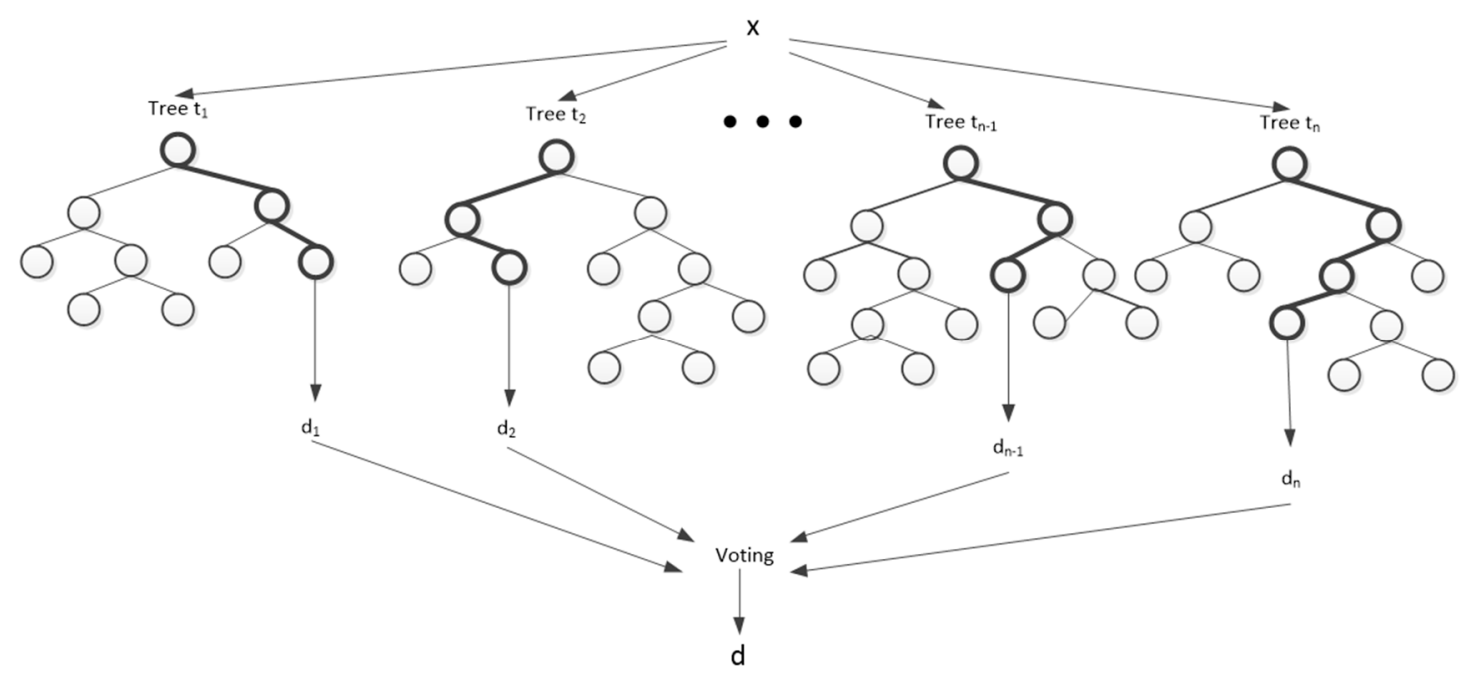

Figure A1. Random Forests adapted from Nguyen et al. [76].

Appendix B.4 Linear Regression Model

This study use Linear Regression Model as it can acquire the additive relationships between the independent variables and the dependent variables. Equation (A2) is shown to identify which classification the user belongs to.

$$
\hat{Y}_{t}=b_{0}+b_{1} X_{1 t}+b_{2} X_{2 t}+\cdots+b_{k} X_{k t}
$$

where $Y$ denotes the dependent variable we wish to predict, $X_{1}, X_{2}, \cdots, X_{k}$ denote the independent variable, the training set, with the value of $X_{i t}$ at each time of interaction and $b_{1}, b_{2}, \cdots, b_{k}$ is the coefficients of the independent variables. Table A4 presents the original results of Linear Regression prediction.

Table A4. The result of linear regression prediction.

\begin{tabular}{ccccc}
\hline Actual & Predicted & $\mathbf{0}$ & $\mathbf{1}$ & Error \\
\cline { 1 - 3 } 0 & 0.02 & 0.22 & 0.91 \\
1 & 0.01 & 0.74 & 0.01 \\
\hline
\end{tabular}

Appendix B.5 Support Vector Machine (SVM) Model

SVM Model is a discriminative classification method to define an optimal hyperplane for prediction. Specifically, the inputs are the training set, and the output is an optimal hyperplane that can group users into different categories. Figure A2 shows the initial results of multiple hyperplanes based on algorithms, while the SVM Model can further reach the optimal one which can achieve the maximum margin (see Figure A3). Table A5 shows the original outputs of SVM prediction.

Table A5. The results of SVM prediction.

\begin{tabular}{ccccc}
\hline Actual & Predicted & $\mathbf{0}$ & $\mathbf{1}$ & Error \\
\hline 0 & & 0.00 & 0.24 & 1 \\
1 & 0.00 & 0.76 & 0 \\
\hline
\end{tabular}




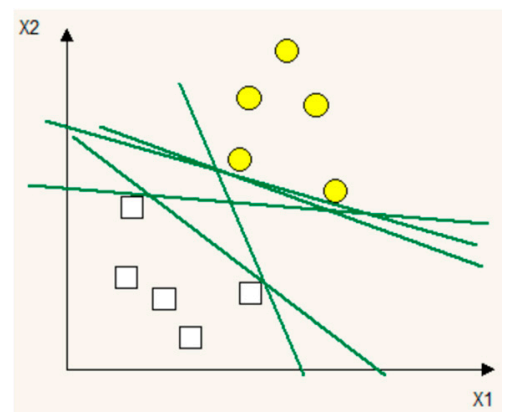

Figure A2. Multiple optimal hyperplanes (green lines) that that can group user into different groups.

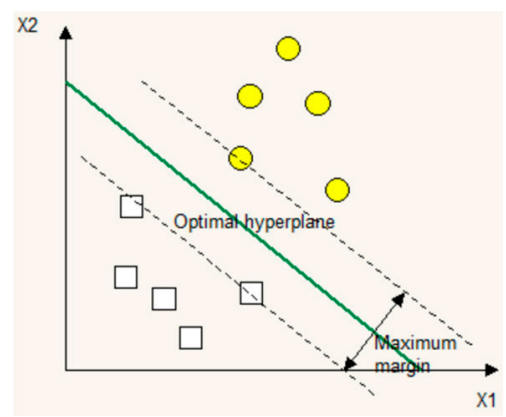

Figure A3. The optimal hyperplane (green line) from SVM Model.

\section{Appendix B.6 Neural Network Model}

As a black box tool for accurate prediction, Neural Network Model is very similar to SVM Model. The architecture of a Neural Network prediction is shown in Figure A4. In this study, the inputs are the demographic factor provided by the respondents. Based on the calculation of weight and activation function, Neural Network Model can predict users behaviour considered as the output. The original results of Neural Network prediction are demonstrated in Table A6.

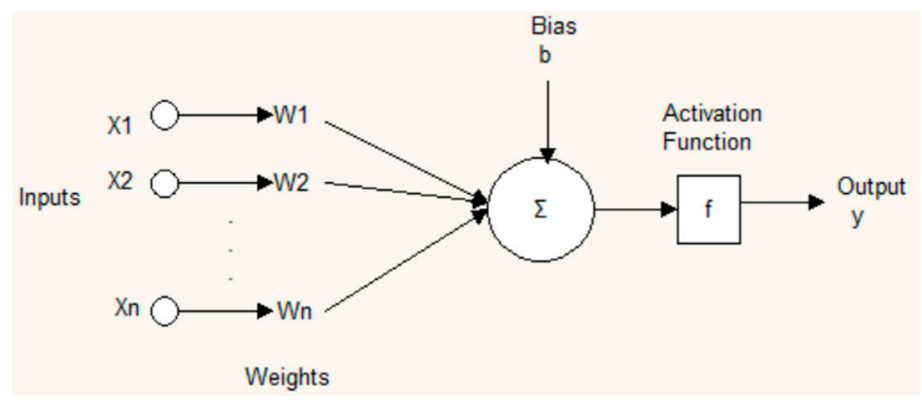

Figure A4. Architecture of a Neural Network prediction.

Table A6. The results of Neural Network prediction.

\begin{tabular}{ccccc}
\hline Actual & Predicted & $\mathbf{0}$ & $\mathbf{1}$ & Error \\
\cline { 1 - 3 } 0 & & 0.04 & 0.20 & 0.83 \\
1 & 0.06 & 0.69 & 0.08 \\
\hline
\end{tabular}




\section{References}

1. Pakpour, A.H.; Zeidi, I.M.; Emamjomeh, M.M.; Asefzadeh, S.; Pearson, H. Household waste behaviours among a community sample in Iran: An application of the theory of planned behaviour. Waste Manag. 2014, 34, 980-986. [CrossRef] [PubMed]

2. Amir, M.; Karim, M.; Mourad, B.B.; Amar, T. Design and development of a low cost technique for sorting household wastes using eddy current separation process. Int. J. Environ. Stud. 2016, 73, 203-213. [CrossRef]

3. Nijhof, G.H. Aluminium separation out of household waste using the eddy current technique and re-use of the metal fraction. Resour. Conserv. Recycl. 1994, 10, 161-169. [CrossRef]

4. Grazhdani, D. Assessing the variables affecting on the rate of solid waste generation and recycling: An empirical analysis in Prespa Park. Waste Manag. 2016, 48, 3-13. [CrossRef] [PubMed]

5. Kirakozian, A. The determinants of household recycling: Social influence, public policies and environmental preferences. Appl. Econ. 2016, 48, 1481-1503. [CrossRef]

6. Sidique, S.F.; Joshi, S.V.; Lupi, F. Factors influencing the rate of recycling: An analysis of minnesota counties. Resour. Conserv. Recycl. 2010, 54, 242-249. [CrossRef]

7. Dinan, T.M. Economic efficiency aspects of alternative policies for reducing waste disposal. J. Environ. Econ. Manag. 1993, 25, 242-256. [CrossRef]

8. Nzeadibe, T.C.; Anyadike, R.N.C. Social Participation in city governance and urban livelihoods: Constraints to the informal recycling economy in Aba, Nigeria. City Cult. Soc. 2012, 3, 313-325. [CrossRef]

9. Scheinberg, A.; Spies, S.; Simpson, M.H.; Mol, A.P.J. Assessing urban recycling in low- and middle-income countries: Building on modernised mixtures. Habitat Int. 2011, 35, 188-198. [CrossRef]

10. Sternberg, C.A. From 'Cartoneros' to 'Recolectores Urbanos'. The changing rhetoric and urban waste management policies in Neoliberal Buenos Aires. Geoforum 2013, 48, 187-195. [CrossRef]

11. Babaei, A.A.; Alavi, N.; Goudarzi, G.; Teymouri, P.; Ahmadi, K.; Rafiee, M. Household recycling knowledge, attitudes and practices towards solid waste management. Resour. Conserv. Recycl. 2015, 102, 94-100. [CrossRef]

12. Chu, P.Y.; Chiu, J.-F. Factors influencing household waste recycling behavior: Test of an integrated mode. J. Appl. Soc. Psychol. 2003, 33, 604-626. [CrossRef]

13. De Groot, J.I.M.; Steg, L. Relationships between value orientations, self-determined motivational types and pro-environmental behavioral intentions. J. Environ. Psychol. 2010, 30, 368-378. [CrossRef]

14. Hoyos, D.; Mariel, P.; Fernandez-Macho, J. The influence of cultural identity on the wtp to protect natural resources: Some empirical evidence. Ecol. Econ. 2009, 68, 2372-2381. [CrossRef]

15. Pakpour, A.H.; Sniehotta, F.F. Perceived behavioural control and coping planning predict dental brushing behaviour among Iranian adolescents. J Clin. Periodontol. 2012, 39, 132-137. [CrossRef] [PubMed]

16. Pakpour, A.H.; Zeidi, I.M.; Chatzisarantis, N.; Molsted, S.; Harrison, A.P.; Plotnikoff, R.C. Effects of action planning and coping planning within the theory of planned behaviour: A physical activity study of patients undergoing. Psychol. Sport Exerc. 2011, 12, 609-614. [CrossRef]

17. Schultz, P.W. The structure of environmental concern: Concern for self, other people, and the biosphere. J. Environ. Psychol. 2001, 21, 327-339. [CrossRef]

18. Ajzen, I. The theory of planned behavior. Organ. Behav. Hum. Decis. Process. 1991, 50, 179-211. [CrossRef]

19. Feldman, J.M.; Lynch, J.G. Self-generated validity and other effects of measurement on belief, attitude, intention, and behavior. J. Appl. Psychol. 1988, 73, 421-435. [CrossRef]

20. Wan, C.; Shen, G.Q.; Yu, A. Key determinants of willingness to support policy measures on recycling: A case study in Hong Kong. Environ. Sci. Policy 2015, 54, 409-418. [CrossRef]

21. Tonglet, M.; Phillips, P.S.; Bates, M.P. Determining the drivers for householder pro-environmental behaviour: Waste minimisation compared to recycling. Resour. Conserv. Recycl. 2004, 42, 27-48. [CrossRef]

22. Chan, K. Mass communication and pro-environmental behaviour: Waste recycling in Hong Kong. J. Environ. Manag. 1998, 52, 317-325. [CrossRef]

23. Schutte, N.S.; Malouff, J.M.; Bobik, C.; Coston, T.D.; Greeson, C.; Jedlicka, C.; Rhodes, E.; Wendorf, G. Emotional intelligence and interpersonal relations. J. Soc. Psychol. 2001, 141, 523-536. [CrossRef] [PubMed]

24. Ajzen, I. Perceived behavioral control, self-efficacy, locus of control, and the theory of planned Behavior1. J. Appl. Soc. Psychol. 2002, 32, 665-683. [CrossRef]

25. Sniehotta, F.F.; Scholz, U.; Schwarzer, R. Bridging the intention-behaviour gap: Planning, self-efficacy, and action control in the adoption and maintenance of physical exercise. Psychol. Health 2005, 20, 143-160. [CrossRef] 
26. Stefan, V.; van Herpen, E.; Tudoran, A.A.; Lähteenmäki, L. Avoiding food waste by Romanian consumers: The importance of planning and shopping routines. Food Qual. Preference 2013, 28, 375-381. [CrossRef]

27. Mondéjar-Jiménez, J.A.; Ferrari, G.; Secondi, L.; Principato, L. From the table to waste: An exploratory study on behaviour towards food waste of Spanish and Italian youths. J. Clean. Prod. 2016, 138, 8-18. [CrossRef]

28. Quested, T.E.; Marsh, E.; Stunell, D.; Parry, A.D. Spaghetti soup: the complex world of food waste behaviours. Resour. Conserv. Recycl. 2013, 79, 43-51. [CrossRef]

29. Zhang, D.; Huang, G.; Yin, X.; Gong, Q. Residents' waste separation behaviors at the source: Using SEM with the theory of planned behavior in Guangzhou, China. Int. J. Environ. Res. Pub. Health 2015, 12, 9475-9491. [CrossRef] [PubMed]

30. Barr, S.; Gilg, A.W. A conceptual framework for understanding and analyzing attitudes towards environmental behaviour. Geogr. Ann. Ser. B 2007, 89, 361-379. [CrossRef]

31. Kollmuss, A.; Agyeman, J. Mind the gap: Why do people act environmentally and what are the barriers to pro-environmental behavior? Environ. Educ. Res. 2002, 8, 239-260. [CrossRef]

32. Thøgersen, J.; Noblet, C. Does green consumerism increase the acceptance of wind power? Energy Policy 2012, 51, 854-862. [CrossRef]

33. Nguyen, T.N.; Lobo, A.; Nguyen, H.L.; Phan, T.T.H.; Cao, T.K. Determinants influencing conservation behaviour: Perceptions of Vietnamese consumers. J. Consum. Behav. 2016, 15, 560-570. [CrossRef]

34. Tang, Z.; Chen, X.; Luo, J. Determining socio psychological drivers for rural household recycling behavior in developing countries: A case study from Wugan, Hunan, China. Environ. Behav. 2011, 43, 848-877. [CrossRef]

35. Yuan, Y.; Nomura, H.; Takahashi, Y.; Yabe, M. Model of Chinese household kitchen waste separation behavior: A case study in Beijing city. Sustainability 2016, 8, 1083. [CrossRef]

36. Samdahl, D.M.; Robertson, R. Social determinants of environmental concern: Specification and test of the Model. Environ. Behav. 1989, 21, 57-81. [CrossRef]

37. Botetzagias, I.; Dima, A.F.; Malesios, C. Extending the theory of planned behavior in the context of recycling: The role of moral norms and of demographic predictors. Resour. Conserv. Recycl. 2015, 95, 58-67. [CrossRef]

38. Steg, L.; Vlek, C. Encouraging pro-environmental behaviour: An integrative review and research agenda. J. Environ. Psychol. 2009, 29, 309-317. [CrossRef]

39. Wan, C.; Shen, G.Q.; Yu, A. The moderating effect of perceived policy effectiveness on recycling intention. J. Environ. Psychol. 2014, 37, 55-60. [CrossRef]

40. Wan, C.; Shen, G.Q.; Yu, A. The role of perceived effectiveness of policy measures in predicting recycling behaviour in Hong Kong. Resour. Conserv. Recycl. 2014, 83, 141-151. [CrossRef]

41. Karim Ghani, W.A.W.A.; Rusli, I.F.; Biak, D.R.A.; Idris, A. An application of the theory of planned behaviour to study the influencing factors of participation in source separation of food waste. Waste Manag. 2013, 33, 1276-1281. [CrossRef] [PubMed]

42. Nigbur, D.; Lyons, E.; Uzzell, D. Attitudes, norms, identity and environmental behaviour: Using an expanded theory of planned behaviour to predict participation in a kerbside recycling programme. Br. J. Soc. Psychol. 2010, 49, 259-284.

43. Valle, P.O.; Reis, E.; Menezes, J.; Rebelo, E. Behavioral determinants of household recycling participation: The Portuguese case. Environ. Behav. 2004, 36, 505-540. [CrossRef]

44. Shaw, P.J. Nearest neighbour effects in kerbside household waste recycling. Resour. Conserv. Recycl. 2008, 52, 775-784. [CrossRef]

45. Bentler, P.M.; Speckart, G. Models of attitude-behavior relations. Psychol. Rev. 1979, 86, 452-464. [CrossRef]

46. Fredricks, A.J.; Dossett, D.L. Attitude-behavior relations: A comparison of the Fishbein-Ajzen and the Bentler-Speckart Models. J. Pers. Soc. Psychol. 1983, 45, 501-512. [CrossRef]

47. Carrus, G.; Passafaro, P.; Bonnes, M. Emotions, habits and rational choices in ecological behaviours: The case of recycling and use of public transportation. J. Environ. Psychol. 2008, 28, 51-62. [CrossRef]

48. Guagnano, G.A.; Stern, P.C.; Dietz, T. Influences on attitude-behavior relationships. Environ. Behav. 1995, 27, 699-718. [CrossRef]

49. Rodríguez, O.; Guzmán, M.; Hans, J.; Mosler, A.; Tamas, R.; Tobias, T. Deriving interventions on the basis of factors influencing behavioral iintentions for waste recycling, Composting, and Reuse in Cuba. Environ. Behav. 2008, 40, 522-544.

50. Pinsonneault, A.; Kraemer, K. Survey research methodology in management information systems: An assessment. J. Manag. Inf. Syst. 1993, 10, 75-105. [CrossRef] 
51. Kidder, L.H.; Fine, M. Qualitative and quantitative methods: when stories converge. New Direct. Evaluat. 1987, 1987, 57-75. [CrossRef]

52. Average Salary in Major Chinese Cities Is $\$ 900$ and Growing. 2016. Available online: http:/ / www.chinadaily. com.cn/china/2016-01/21/content_23183484.htm (accessed on 21 January 2017).

53. Fornell, C.; Larcker, D.F. Evaluating structural equation models with unobservable variables and measurement error. J. Market. Res. 1981, 18, 39-50. [CrossRef]

54. Campbell, D.T.; Fiske, D.W. Convergent and discriminant validation by the multitrait-multimethod matrix. Psychol. Bull. 1959, 56, 81. [CrossRef] [PubMed]

55. Bem, D.J. Self-perception theory. Adv. Exp. Soc. Psychol. 1972, 6, 1-62.

56. Madden, T.J.; Ellen, P.S.; Ajzen, I. A comparison of the theory of planned behavior and the theory of reasoned action. Personal. Soc. Psychol. Bull. 1992, 18, 3-9. [CrossRef]

57. Boldero, J. The prediction of household recycling of newspapers: The role of attitudes, intentions, and situational factors. J. Appl. Soc. Psychol. 1995, 25, 440-462. [CrossRef]

58. Abbott, A.; Nandeibam, S.; O'Shea, L. Recycling: Social norms and warm-glow Revisited. Ecol. Econ. 2013, 90, 10-18. [CrossRef]

59. Nyborg, K.; Howarth, R.B.; Brekke, K.A. Green consumers and public policy: On socially contingent moral motivation. Resour. Energy Econ. 2006, 28, 351-366. [CrossRef]

60. Sánchez, M.; López-Mosquera, N.; Lera-López, F. Improving pro-environmental behaviours in Spain. The role of attitudes and socio-demographic and political factors. J. Environ. Policy Plan. 2016, 18, 1-20.

61. Asensio, O.I.; Delmas, M.A. Nonprice incentives and energy conservation. Proc. Natl. Acad. Sci. USA 2015, 112, 510-515. [CrossRef] [PubMed]

62. Akil, A.M.; Foziah, J.; Ho, C.S. The effects of socio-economic influences on households recycling behaviour in Iskandar Malaysia. Proc. Soc. Behav. Sci. 2015, 202, 124-134. [CrossRef]

63. Czajkowski, M.; Hanley, N.; Nyborg, K. Social norms, morals and self-interest as determinants of pro-environment behaviours: The case of household recycling. Environ. Resour. Econ. 2017, 66, 647-670. [CrossRef]

64. Unler, A.; Murat, A. A discrete particle swarm optimization method for feature selection in binary classification problems. Eur. J. Oper. Res. 2010, 206, 528-539. [CrossRef]

65. Ahmeda, S.A.; Ali, M. Partnerships for solid waste management in developing countries: Linking theories to realities. Habitat Int. 2004, 28, 467-479. [CrossRef]

66. Baud, I.; Grafakos, S.; Hordijk, M.; Post, J. Quality of life and alliances in solid waste management: Contributions to urban sustainable development. Cities 2001, 18, 3-12. [CrossRef]

67. Mbiba, B. Urban solid waste characteristics and household appetite for separation at source in Eastern and Southern Africa. Habitat Int. 2014, 43, 152-162. [CrossRef]

68. Nzeadibe, T.C. Solid waste reforms and informal recycling in Enugu urban area, Nigeria. Habitat Int. 2009, 33, 93-99. [CrossRef]

69. Parrot, L.; Sotamenou, J.; Dia, B.K. Municipal solid waste management in Africa: Strategies and livelihoods in Yaoundé, Cameroon. Waste manag. 2009, 29, 986-995. [CrossRef] [PubMed]

70. Nguyen, T.T.P.; Zhu, D.; Le, N.P. Factors influencing waste separation intention of residential households in a developing country: Evidence from Hanoi, Vietnam. Habitat Int. 2015, 48, 169-176. [CrossRef]

71. Quinlan, J.R. Induction of decision trees. Mach. Learn. 1986, 1, 81-106. [CrossRef]

72. Adomavicius, G.; Tuzhilin, A. Using data mining methods to build customer profiles. Computer 2001, 34, 74-82. [CrossRef]

73. Liu, Y.; Yao, X. Ensemble learning via negative correlation. Neural Netw. 1999, 12, 1399-1404. [CrossRef]

74. Assaad, M.; Boné, R.; Cardot, H. A new boosting algorithm for improved time-series forecasting with recurrent neural networks. Inf. Fusion 2008, 9, 41-55. [CrossRef]

75. Xia, R.; Zong, C.; Li, S. Ensemble of feature sets and classification algorithms for sentiment classification. Inf. Sci. 2011, 181, 1138-1152. [CrossRef]

76. Nguyen, C.; Wang, Y.; Nguyen, H.N. Random forest classifier combined with feature selection for breast cancer diagnosis and prognostic. J. Biomed. Sci. Eng. 2013, 6, 551-560. [CrossRef]

(C) 2017 by the authors. Licensee MDPI, Basel, Switzerland. This article is an open access article distributed under the terms and conditions of the Creative Commons Attribution (CC BY) license (http:/ / creativecommons.org/licenses/by/4.0/). 